\title{
Manuel de Falla catalanófilo: la sardana y la sonoridad de la cobla en Atlántida
}

\section{Manuel de Falla as a Catalanophile:The Sardana and the Sound of the Cobla in Atlántida}

Manuel de Falla (1876-1946) conoció la sardana, la cobla y el timbre de sus instrumentos durante sus estancias en Barcelona. El músico, que tenía una especial predilección por Cataluña, mostró mucho interés por todo lo que rodeaba la formación y el género musical de origen popular. Este artículo recoge las crónicas de los conciertos y ensayos de la Cobla Barcelona a los que Manuel de Falla asistió, así como su opinión, una concepción narrada en unos términos que, aún hoy en día, contribuyen a definir la noción de la sardana y la cobla. Finalmente, indaga hasta qué punto esa seducción incitó al músico a incluir la sonoridad de la cobla en Atlántida, una obra que parte del poema L'Atlàntida de JacintVerdaguer, y que Falla dejó inacabada.

Palabras clave: Manuel de Falla, Atlántida, cobla, sardana, Cataluña, Cobla Barcelona, siglo XX.

Manuel de Falla (1876-1946) became familiar with the sardana, the cobla and the timbre of its instruments during his visits to Barcelona. The composer, who had a special predilection for Catalonia, showed a great interest in everything to do with the ensemble and music of a popular origin. This article includes the chronicles of the concerts and rehearsals of the Cobla Barcelona that Manuel de Falla attended, as well as his opinion, an account that, even today, helps to define the notion of sardana and cobla. Finally, it explores to what extent this attraction prompted the composer to include the sound of the cobla in Atlántida, a work based on Jacint Verdaguer's poem L'Atlàntida, which Falla left incomplete.

Keywords: Manuel de Falla, Atlántida, cobla, sardana, Catalonia, Cobla Barcelona, 20th century.

\section{Introducción}

Durante las primeras décadas del siglo XX, la sardana, la cobla y el timbre de sus instrumentos se consolidaron en los contextos de la música sinfónica y de cámara, unos ambientes directamente relacionados con las salas de concierto ${ }^{1}$. Las autoridades musicales que visitaron Barcelona durante la década de 1920 cono-

\footnotetext{
${ }^{1}$ Albert Fontelles-Ramonet: "La sardana segons Joaquín Turina", Revista Catalana de Musicologia, Barcelona, 2020, pp. 264-26513, 2020, pp. 264-265.
} 
cieron estos elementos en las distintas audiciones de música catalana que se organizaron en su honor. Estos recitales, que abarcaban diferentes obras relacionadas con Cataluña, contaban con la participación de solistas y agrupaciones musicales catalanas, entre las cuales destacaba la Cobla Barcelona. Estas audiciones, ideadas para fomentar y divulgar el patrimonio musical catalán, fueron impulsadas por la sociedad civil, aunque en determinadas épocas llegaron a formar parte de los programas culturales de las instituciones políticas catalanas ${ }^{2}$.

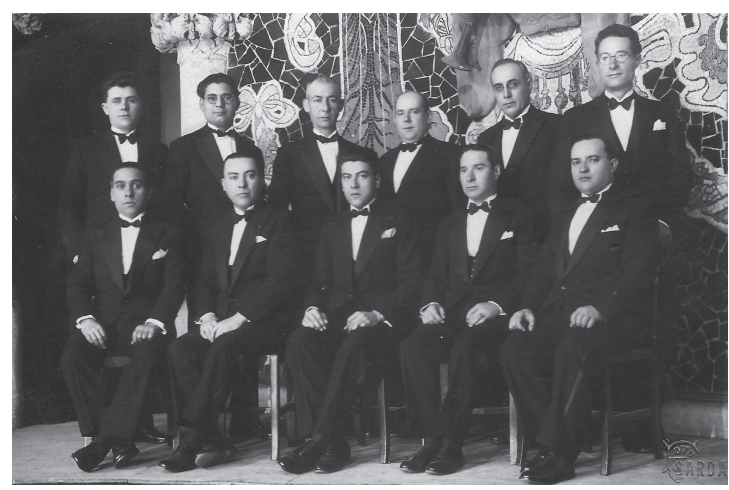

Ilustración 1. La Cobla Barcelona en el Palau de la Música Catalana en 1929 (Colección del autor)

La Cobla Barcelona se presentó el 30 de marzo de 1922 en el Teatre Tívoli. En pocos años, logró un importante protagonismo en la vida cultural catalana. Actuó en espacios emblemáticos, como el Palau de la Música Catalana, el Gran Teatre del Liceu, el Palau de Belles Arts o el Palau Nacional de Catalunya; y estrenó obras de los más importantes compositores catalanes, como Juli Garreta, Ricard Lamote de Grignon, Enric Morera, Francesc Pujol, Joaquim Serra, Eduard Toldrà y AmadeuVives. También participó en eventos destacados, como en actos oficiales de la Exposición Internacional de Barcelona (1929), la Exposición Iberoamericana de Sevilla (1929), las fiestas de la proclamación de la República en Madrid (1932), el concierto-homenaje al presidente del Gobierno de la República (1932), o el XIV Festival de la Sociedad Internacional de Música Contemporánea y de la Sociedad Internacional de Musicología (1936). En 1932, el Gobierno de la Generalitat le otorgó la distinción de "Cobla Oficial de la Generalitat de Catalunya". Durante la Guerra Civil hizo dos giras por Europa organizadas por el Comisariado de Propaganda de la Generalitat y actuó, además de en la inauguración del pabellón de España de la Exposición Internacional de París (1937), en varias salas parisinas: la Sala Gaveau, la Sala

\footnotetext{
2 "La visita d'Einstein", Catalunya Gràfica, Barcelona, abril 1923, p. 8. En 1923 la Mancomunitat de Catalunya organizó un recital de la Cobla Barcelona en honor al científico Albert Einstein.
} 
Pleyel o el Grand Palais des Champs-Élysées. En 1938, enmudeció. Sin embargo, la formación pudo refundarse en 1945 con un replanteamiento entendido dentro del regionalismo franquista ${ }^{3}$.

Durante la década de 1920, la Cobla Barcelona ofreció conciertos a Harold Bauer, Béla Bartók, Manuel de Falla, Arthur Honneger, Clemens Krauss, Darius Milhaud, Max von Schillings, Kurt Schindler, Richard Strauss e Igor Stravinsky ${ }^{4}$. Los promotores de estos recitales recogían la opinión de los músicos, un juicio que contribuía a valorar y a dignificar la formación y el patrimonio musical que interpretaba. Incluso, en algunas ocasiones, intentaron seducirlos para que escribieran una obra para la formación. Estas audiciones contribuyeron a darle visibilidad y a dirigir atención hacia la cobla y encarnaron la idea de cómo un conjunto instrumental, imaginado como catalán y antiguo, podía ser revestido de modernidad e incluso de vanguardia, una determinada concepción que dialogaba con la tradición y que encajaba con los ideales del neoclasicismo musical.

\section{Manuel de Falla y la Cobla Barcelona}

En febrero de 1925, la Associació Música da Camera dedicó dos sesiones a Manuel de Falla en el Palau de la Música Catalana, con la Orquesta Bética de Cámara dirigida por el propio compositor y por un joven Ernesto Halffter. El primer concierto, celebrado el día 7 de febrero, incluyó $\mathrm{Ka}$ marinskaïa de Glinka, la Sinfonieta en La menor de Rimski-Kórsakov y dos primeras audiciones de Falla: El amor brujo y El retablo de maese Pedro ${ }^{5}$. El segundo concierto, celebrado a los dos días, englobó la Sinfonía en Sol menor de Mozart con obras del músico andaluz: El sombrero de tres picos, El retablo de maese Pedro, "Danza del ritual del fuego" de El amor brujo y un estreno, Psyché.

Durante la estancia, Falla asistió a un concierto de la Banda Municipal de Barcelona. El 8 de febrero, invitado por Joan Lamote de Grignon y acompañado por Miquel Llobet y Slavianski Agreneff, escuchó desde un balcón de la plaza del Rei la obertura Dinorah de Giacomo Meyerbeer, Tres danses mallorquines de Antoni Noguera, Canigó de Jaume Pahissa, L'Apprenti sorcier de Paul Dukas, Mignon de Ambroise Thomas, la Rapsodia española de Isaac Albéniz y la

\footnotetext{
${ }^{3}$ Albert Fontelles-Ramonet: La Cobla Barcelona (1922-1938). Un projecte noucentista, tesis doctoral, Universitat Autònoma de Barcelona, 2020.

${ }^{4}$ Ibid.

5 "Primera sessió dedicada al mestre Manuel de Falla a càrrec de l'Orquestra Bética de Cámara, 7-21925", Barcelona, Centre de Documentació de l'Orfeó Català, Colección de programas de concierto, http:// mdc.csuc.cat/cdm/search/collection/ProgPMC (consulta 5-2-2021).

${ }^{6}$ Marta Muntada: L’Associació Música "Da Camera" (1913-1936), tesis de licenciatura, Universitat de Barcelona, 1984, p. 130.
} 
obertura de Tannhäuser de Richard Wagner ${ }^{7}$. Al finalizar, Falla felicitó a Lamote y expresó la admiración que le causaba la "depuradísima tarea de la banda", una institución "de gran valor”, según el músico .

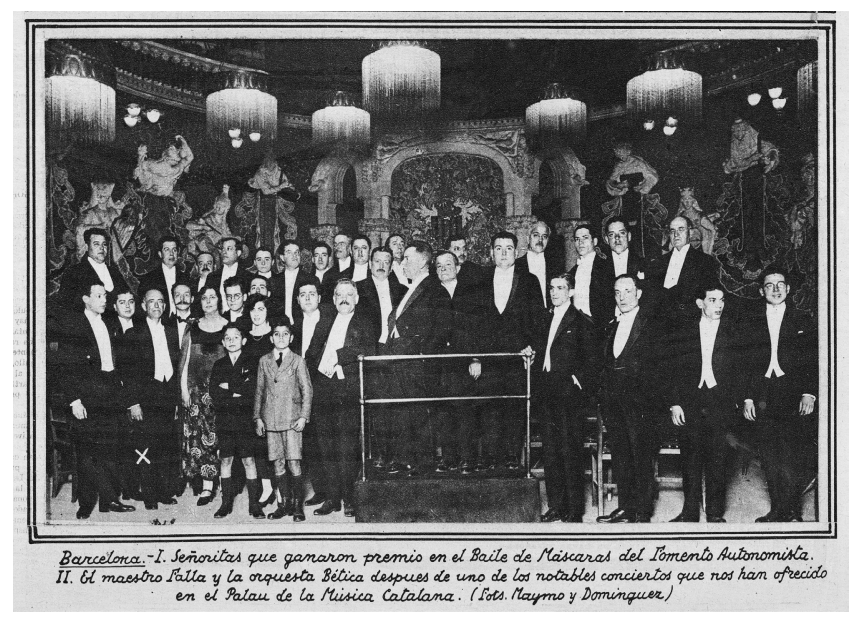

Ilustración 2. Manuel de Falla, Ernesto Halffter, Mercè Plantada y la Orquestra Bética de Cámara en el Palau de la Música Catalana, febrero de 1925, La Noche, Barcelona, 11-2-1925, p. 1

El 14 de febrero, Manuel de Falla asistió a un ensayo de la Banda Municipal de Barcelona y de la Cobla Barcelona en el Palau de Belles Arts, acompañado por Miquel Llobet, Eduard Toldrà, Francesc Blanch, Joan Gisbert y Rafael Moragas. Falla, que ya había escuchado la formación hacía unos días, decidió revivir de nuevo la experiencia en un contexto no público. Este evento supuso una proximidad muy directa del músico con la banda, así como con la cobla y la sonoridad de los instrumentos que la conforman. Tras escuchar Evocación y Corpus Christi en Sevilla de la suite Iberia de Albéniz, Falla felicitó nuevamente a Lamote, y el director le contó que estaba terminando la transcripción para banda de la "Danza del ritual del fuego" de El amor brujo ${ }^{10}$.

7 "Falla i la Banda Municipal", La Veu de Catalunya, Barcelona, 9-2-1925, p. 2.

${ }^{8}$ Ibid.: "El mestre Falla expressà reiteradament l'admiració que li causava la depuradíssima tasca de la nostra Banda, i enaltí a aquest corporació com a organisme de gran vàlua".

${ }^{9}$ Ibid.

10 "Sardanes", La Veu de Catalunya, Barcelona, 15-2-1925, p. 3; "Honorant el mestre Falla", Revista Musical Catalana, Barcelona, febrero 1927, p. 33; Juan Carlos Galiano: "El amor brujo en el repertorio actual de banda (2006-2015): hacia un estado de la cuestión", El amor brujo, metáfora de la modernidad: estudios en torno a Manuel de Falla y la música española del siglo XX, Madrid, Centro de Documentación de Música y Danza, INAEM / Granada, Archivo Manuel de Falla, 2017, pp. 499-518. 


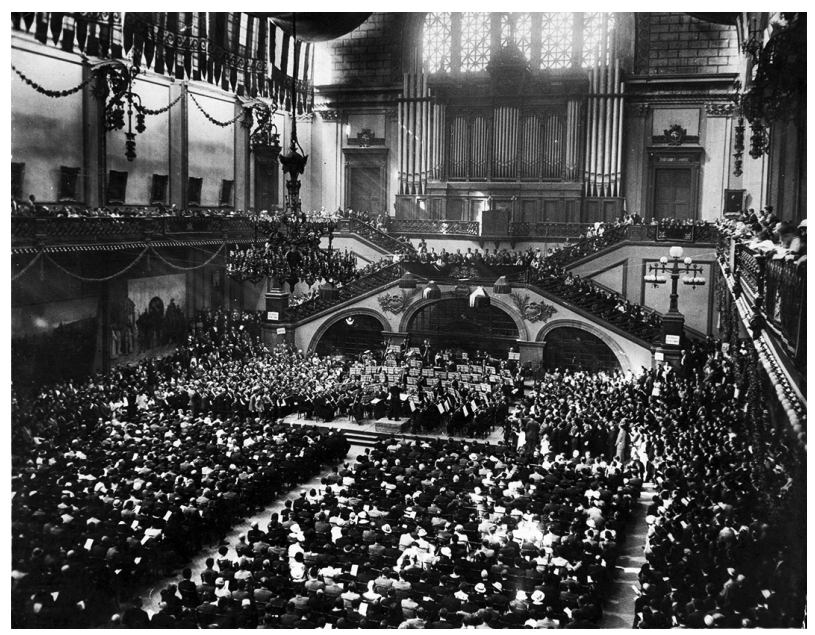

Ilustración 3. Concierto de la Banda Municipal de Barcelona en el Palau de Belles Arts, década de 1930 (Fondo José Subirá, Biblioteca de Catalunya)

Seguidamente, la Cobla Barcelona le ofreció un recital de sardanas. Según el cronista de LaVeu de Catalunya, Falla quedó muy satisfecho y felicitó efusivamente al intérprete solista de tenora, Albert Marti ${ }^{11}$. Desconocemos las sardanas que interpretó la formación, pero podemos hacer una estimación basada en los hechos y en el repertorio que tocaba en aquellas fechas. Por un lado, sabemos que Lamote de Grignon y Toldrà estuvieron presentes en el acto, el primero dirigía la banda y el segundo acompañaba a Falla ${ }^{12}$. Por lo tanto, podría ser que la cobla interpretara Rosa del folló de Lamote de Grignon -una de las obras más divulgadas por la Cobla Barcelona durante aquellos años ${ }^{13}$-junto con una sardana de Toldrà: El bac de les ginesteres -interpretada por la cobla en el Palau de la Música en enero de $1925^{14}$ - o Caterina d' Alio ${ }^{15}$. Por otra parte, antes de terminar la temporada ${ }^{16}$, la cobla había interpretado composiciones que también podían haber sonado: Setembre y Heroica de Enric Casals -hermano de Pau Casals $-{ }^{17}$, Cecília de Antoni Juncà ${ }^{18}$, A en Pau Casals de Juli Garreta ${ }^{19}$ y Davant la verge de Enric Morera ${ }^{20}$.

\footnotetext{
11 Ibid.

12 Ibid.

${ }^{13}$ A. Fontelles-Ramonet: La Cobla Barcelona...

14 “Cap d'Any, Orfeó Català i Cobla Barcelona”, Revista Musical Catalana, Barcelona, enero 1925, p. 12.

15 "Sardanes", La Veu de Catalunya, Barcelona, 14-2-1925, p. 6.

${ }^{16}$ Las coblas finalizaban la temporada y renovaban el repertorio durante la Cuaresma, coincidiendo con la finalización de contratos y los cambios de intérpretes. Hoy en día, la mayoría de coblas mantienen este calendario.

17 "Cap d'Any...", p. 12; "Sardanes", La Veu de Catalunya, Barcelona, 11-1-1925, p. 2.

18 "Sardanes", La Veu de Catalunya, Barcelona, 15-1-1925, p. 1.

${ }^{19}$ Ibid.

20 "Sardanes", La Veu de Catalunya, Barcelona, 1-2-1925, p. 3.
} 
Al finalizar el recital de sardanas, ocurrió un hecho remarcable: Falla firmó el libro de honor ${ }^{21}$ y prometió a Lamote de Grignon que escribiría una obra para banda ${ }^{22}$, una composición que, a pesar de los múltiples ruegos del director ${ }^{23}$, nunca llegó a escribir. Horas antes de coger el tren con destino a Granada, Falla asistió al banquete de despedida que le organizaron en el Hotel Majestic, donde agradeció la acogida y exclamó: "Yo he de deciros, y lo digo con toda el alma, que, sin los catalanes, acaso no hubiera podido llegar a realizar mi obra, ni a ser quién soy" ${ }^{24}$.Y es que el triunfo de los conciertos de Falla en la Barcelona de 1925 -en plena dictadura de Primo de Rivera- llevó La Veu de Catalunya a dedicarle un editorial titulado: "El camino para la convivencia cordial de las tierras de España" 25 . El redactor del diario enfatizó el entendimiento del músico con el público catalán y comparó el hecho artístico y estético de sus obras con el momento político que vivía el país:

El triunfo que ha conseguido el ilustre músico andaluz Manuel de Falla en Barcelona destruye la leyenda de que la capital de Cataluña adopte una actitud sistemáticamente hostil hacia las manifestaciones artísticas de otros pueblos peninsulares [...]. La concepción artística de Manuel de Falla es bastante ancha y generosa para superar todos los prejuicios raciales [...]. No es catalán y ha encontrado naturalísimo que los programas hayan sido redactados en catalán [...]. La política y el arte tienen también sus afinidades, ambas manifestaciones de la actividad humana obedecen a impulsos ideales [...].Y con el mutuo respeto y la mutua comprensión llegaría naturalmente y sin esfuerzo a la mutua simpatía. Es en esta virtud de la comprensión que hay que buscar el camino para una convivencia cordial y fecunda con las tierras de España ${ }^{26}$.

21 "Llibre d'Honor de la Banda Municipal de Barcelona, 1925-1934", Barcelona, Museu de la Música, Col.leccions digitals, MDMB 12267, https://cataleg.museumusica.bcn.cat/d (consulta 30-9-2019). En la p. 2 del libro encontramos la dedicatoria firmada por Manuel de Falla: "Me es gratísimo consignar mi felicitación efusiva a la magnífica Banda Municipal de Barcelona y a su eminente director el maestro Lamote de Grignon. Guardaré el recuerdo de sus audiciones entre los más valiosos de mi estancia en la fuerte y nobilísima capital de Cataluña".

22 "Falla i la Banda Municipal", La Veu de Catalunya, Barcelona, 9-2-1925, p. 2.

${ }^{23}$ Carta de Manuel de Falla a Joan Lamote de Grignon, 24-1-1927, Granada, Archivo Manuel de Falla, Correspondencia, top. 7168-033: "Todo esto, decirle desde hace un mes, por la falta absoluta de tiempo -iese terrible tirano!- no me ha permitido hacerlo hasta hoy. Pienso mucho y con entusiasmo en mi [...] trabajo para la banda"; carta de Joan Lamote de Grignon a Manuel de Falla, 12-9-1927, top. 7168-007: "Me limito a recordarle su promesa de una obra expresamente escrita para esta banda"; carta de Joan Lamote de Grignon a Manuel de Falla, 22-9-1928, top. 7168-009: "Y recordarle que tiene usted prometida una obra para la Banda Municipal, y que la esperamos con ansia".

24 "Anoche en el Majestic", La Noche, Barcelona, 14-2-1925, p. 11.

25 "Amb motiu dels Concerts Falla. El camí per a la convivencia cordial de les terres d'Espanya”, La Veu de Catalunya, Barcelona, 12-2-1925, p. 5.

${ }^{26}$ Ibid.: "El triomf aconseguit per l'illlustre músic andalús en Manuel de Falla a Barcelona destrueix la llegenda que la capital de Catalunya adopti una actitud sistemàticament hostil envers les manifestacions artístiques d'altres pobles peninsulars [...]. La concepció artística d'en Manuel de Falla és prou ampla i 
En noviembre de 1926, la Associació Música da Camera organizó un nuevo Festival Manuel de Falla en el Palau de la Música Catalana. El concierto contó con la Orquesta Pau Casals, la soprano Conxita Badia, la clavecinista Wanda Landowska y la dirección de Manuel de Falla y Pau Casals. La formación interpretó "Danza final" de El sombrero de tres picos; Noches en los jardines de España, con Falla como intérprete; El retablo de maese Pedro y el estreno del Concierto para clave $^{27}$. Josep Juncà, fundador y contrabajista de la Cobla Barcelona ${ }^{28}$, aprovechó el acontecimiento para enviar una carta a Rafael Moragas ${ }^{29}$.

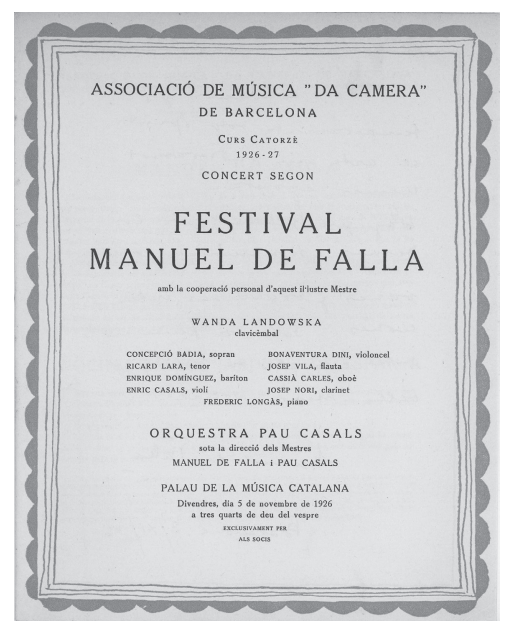

Ilustración 4. Programa del Festival Manuel de Falla celebrado en el Palau de la Música Catalana, 5-11-1926 (Centre de Documentació de l'Orfeó Català)

En esta, evocó el concierto que había ofrecido la cobla en el Palau de Belles Arts, un evento que, según Juncà, había sido impulsado por Moragas. El contrabajista, que conocía la promesa que había hecho Falla a Lamote, propuso la organización de un concierto que incluyera una obra para cobla escrita por Falla:

generosa per a superar tots els prejudicis racials [...]. No és català, i ha trobat naturalíssim que els programes hagin estat redactats en català [...]. La política i l'art tenen també les seves afinitats, ambdues manifestacions de l'activitat humana obeeixen a impulsos ideals [...]. I amb el mutu respecte i la mútua comprensió s'arribaria naturalment i sense esforç a la mútua simpatia. És, doncs, en aquesta virtut de la comprensió que cal cercar encara el camí, per a una convivència cordial i fecunda de les terres Espanya".

27 "Curs catorzé 1926-1927: Concert Segon: Festival Manuel de Falla", Centre de Documentació de l'Orfeó Català, Colección de programas de concierto de l'Orfeó Català, https://mdc.csuc.cat/digital/collection/ProgPMC/id/2000/rec/5 (consulta 24-2-2021).

${ }^{28}$ A. Fontelles-Ramonet: La Cobla Barcelona..., p. 463.

${ }^{29}$ Carta de Josep Juncà a Rafael Moragas, 4-11-1926, Granada, Archivo Manuel de Falla, Correspondencia, top. 7303-065. 
¿No os parece amigo Moragas, que Cataluña debería decir al maestro Falla, al oído, sus frescas y elaboradas melodías, haciéndolas oír por la Cobla Barcelona, y que su corazón y su alma quedaran bien impregnados de las ansias de nuestra música? ¿No os parece, vos que sabéis tanto de cosas de Arte, que sería un gran triunfo para la música catalana que este gran hombre se comprometiera a corresponder al efecto, respeto, admiración, y hasta adoración que tenemos muchos catalanes, por sus obras, por medio de una composición para cobla en forma de glosa o de sardana ? $^{30}$.

Es muy probable que Moragas entregara la carta al compositor en noviembre de 1926. Incluso sería muy probable que, siendo escrita en catalán, la leyeran juntos y la comentaran. Aunque Falla nunca llegó a materializar el proyecto, se reencontró con la Cobla Barcelona al cabo de unos meses ${ }^{31}$. El compositor llegó a la Ciudad Condal el día 13 de marzo de 1927 con el fin de ensayar un programa que formaba parte del ciclo de conciertos que organizaba el Gran Teatre del Liceu $^{32}$. El evento, titulado Festival Falla, incluyó Siete canciones populares españolas, Noches en los jardines de España, El retablo de maese Pedro y fragmentos de El sombrero de tres picos y de El amor brujo; y contó con la colaboración de la Orquesta Pau Casals, dirigida por Falla; y los intérpretes Frank Marshall, Conxita Badia, AlexandreVilalta,Vicens Martí y Enrique Domínguez ${ }^{33}$.

Aprovechando la estancia del músico en Barcelona, la entidad Concerts Blaus organizó un festival de música catalana en honor a Manuel de Falla con el objetivo de constituir "una brillante manifestación de las actividades musicales catalanas por la cual el autor de El retablo podrá formar una idea muy interesante de las diversas modalidades de nuestra vitalidad lírica"34. El concierto, que se celebró el día 20 de marzo en el Teatro Olympia y que editó un programa con un dibujo de Falla hecho por Pablo Picasso, se estructuró en tres partes ${ }^{35}$. La primera, incluyó siete canciones populares interpretadas por el Orfeó de Sants y el Orfeó Montserrat y cinco sardanas ejecutadas por la Cobla Barcelona. La segunda, integró tres danzas bailadas por un esbart y cinco canciones de Frederic Mompou, Joaquim Zamacois, Miquel Marqués, Jaume Pahissa y Eduard Toldrà, que fueron interpretadas por la contralto

\footnotetext{
${ }^{30}$ Ibid: "No us sembla amic Moragas, que Catalunya hauria de dir al mestre Falla, a cau d'orella les seves fresques i elaborades melodies, fent-les oir per la Cobla Barcelona, i que el seu cor i la seva ànima quedessin ben impregnats de les ànsies de la nostra música? No us sembla, vós que'n sabeu tant de coses d'Art, que seria un gran triomf, per la Música Catalana, que aquest gran home es comprometés a correspondre al efecte, respecte, admiració, i fins adoració que tenim molts catalans, per les seves obres, per mitjà d'una composició en forma de glosa o bé de sardana?".

31 "Festival de música catalana en honor de Manuel de Falla", Granada, Archivo Manuel de Falla, top. 1927_0017.

${ }^{32}$ La Noche, Barcelona, 12-3-1927, p. 3.

33 Joan Llongueras: "Festival Falla al Liceu", La Veu de Catalunya, Barcelona, 18-3-1927, p. 10.

${ }^{34}$ Rafael Moragas: "Gran festival en honor del Maestro Falla", La Noche, Barcelona, 16-3-1927, p. 19.

35 "Festival de música catalana en honor de Manuel de Falla", Granada, Archivo Manuel de Falla, top. 1927_0017.
} 
Concepció Callao y el pianista Frederic Longàs. Para finalizar, la Banda Municipal de Barcelona interpretó obras de Josep Sancho Marraco, Antoni Nicolau, Joan Lamote de Grignon e Isaac Albéniz. El epílogo del acto consistió en el estreno de las transcripciones de "Nana" y "Jota" de Siete canciones populares españolas, y "Danza ritual del fuego" de El amor brujo, realizadas por Lamote de Grignon ${ }^{36}$. Los aplausos del público obligaron a Falla a salir al escenario. Después de abrazarse con Lamote, el director le cedió la batuta y Falla dirigió el fragmento de El amor brujo ${ }^{37}$.

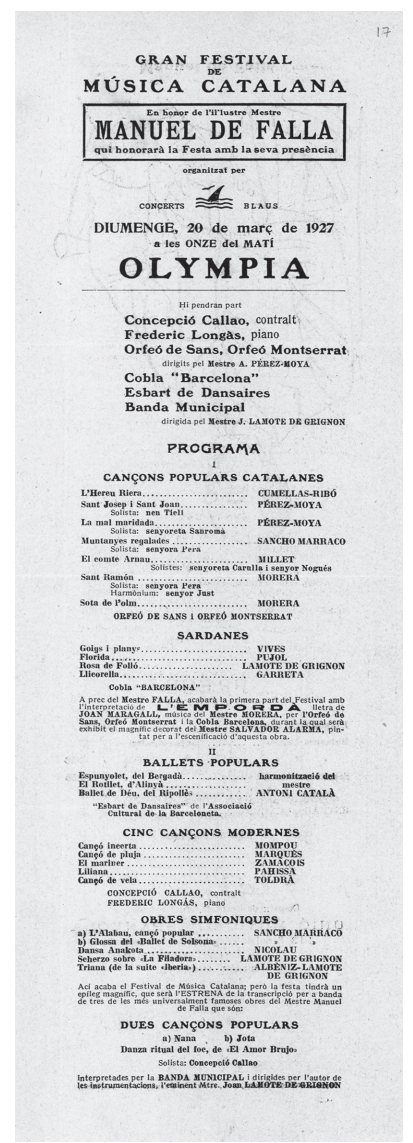

Ilustración 5. Programa del festival en honor a Manuel de Falla celebrado en el Teatro Olympia, 20-3-1927 (Archivo Manuel de Falla)

\footnotetext{
${ }^{36}$ Ibid.

${ }^{37}$ Rafael Moragas: "Gran festival en honor del Maestro Falla", La Noche, Barcelona, 21-3-1927; "Festival en honor a Falla", El Día Gráfico, Barcelona, 22-3-1927, p. 11; "Festival de Música Catalana a l'Olympia", La Veu de Catalunya, Barcelona, 22-3-1927, p. 3; El Día Gráfico, Barcelona, 22-3-1927, p. 11.
} 
Desconocemos si Moragas, que había recibido la carta de Juncà hacía unos meses, intercedió para incluir la Cobla Barcelona en el evento. Sea como sea, el programa de la formación orquestal reunió a autores que habían tenido contacto más o menos directo con el homenajeado: Goig i planys de AmadeuVives, Florida de Francesc Pujol, Rosa del folló de Joan Lamote de Grignon, Llicorella de Juli Garreta y L'Empordà de Enric Morera. La relación entre Falla yVives se remonta a inicios del siglo XX, con la creación conjunta de varias zarzuelas: El cornetín de órdenes, La cruz de Malta y Prisionero de guerra ${ }^{38}$, de las que según Elena Torres solo quedan algunos esbozos en el Archivo Manuel de Falla ${ }^{39}$. Falla concibió la colaboración con Vives como un "real estímulo" ${ }^{40}$ y Vives, a lo largo de los años, valoró así la obra fallesca: "hay en sus obras un sentido genial de perfección en la forma que es, en mi juicio, la esencia misma de la belleza artística" ${ }^{41}$. Con Joan Lamote de Grignon ya habían coincidido durante las múltiples visitas del compositor a Barcelona, quien hizo los ya mencionados elogios de la Banda Municipal de Barcelona. Desconocemos si Falla llegó a conocer a Juli Garreta, pero podemos confirmar que mostró interés por el músico.Aparte de conservar en su archivo personal la Sonata en Do menor para piano ${ }^{42}$, manifestó la voluntad de colaborar económicamente en el proyecto "pro monument a Juli Garreta" iniciado después de la muerte del músico ${ }^{43}$. Falla pidió el funcionamiento de la suscripción a RicardViñes ${ }^{44}$, a Manuel Clausells ${ }^{45}$ y a Joan Gisbert ${ }^{46}$ y al no recibir indicaciones, insistió de nuevo a Gisbert: "Le ruego nuevas noticias sobre lo

\footnotetext{
${ }^{38}$ Antonio Gallego: Catálogo de obras de Manuel de Falla, Madrid, Dirección de Bellas Artes y Archivos, Ministerio de Cultura, 1987, pp. 57-59.

${ }^{39}$ Elena Torres: "Manuel de Falla en la creación musical catalana: asimilación y superación de un modelo", Música española entre dos guerras, 1914-1945, Emilio Casares Rodicio, Javier Suárez-Pajares (coords.), Granada, Publicaciones del Archivo Manuel de Falla, 2002, p. 75; Enrique Mejías: "Manuel de Falla en el contexto del género chico madrileño: nuevas respuestas a un viejo problema", Quodlibet, 55, 2014, pp. 7-39.

${ }^{40}$ Enrique Franco: Amadeo Vives (1871-1971), Madrid, Sociedad General de Autores de España, 1972, p. 82.

${ }^{41}$ Ibid., p. 93.

42 Juli Garreta: Sonata en Do menor, Granada, Archivo Manuel de Falla, AMF 152.

${ }^{43}$ El Monumento a Juli Garreta se encuentra en el paseo marítimo de Sant Feliu de Guíxols, ciudad donde vivió el compositor. Es obra del escultor Enric Monjo Garriga y fue inaugurado en 1932. Consiste en un cuerpo rectangular de piedra que reposa sobre un basamento de considerables dimensiones, también de piedra, y con la inscripción "Garreta" en la parte que mira a la montaña. En esta cara del monumento, destaca un relieve de cobre que representa dos chicas junto a un árbol, imagen típica del Noucentisme.

${ }^{44}$ Carta de Manuel de Falla a Manuel Clausells, 13-7-1927, Granada, Archivo Manuel de Falla, Correspondencia, top. 6843.

${ }^{45}$ Ibid.

${ }^{46}$ Carta de Manuel de Falla a Joan Gisbert, 13-7-1927, Granada, Archivo Manuel de Falla, Correspondencia, top. 7050-2-026(1). "Quisiera contribuir a la suscripción para el monumento a Garreta. ¿Quiere Vd. decirme con toda sinceridad si 25 pesetas sería una cuota decorosa, o hasta cuánto debo aumentarla en caso contrario?".
} 
del monumento a Garreta, reiterándole el deseo de contribuir a la suscripción muy decentemente" ${ }^{47}$. La voluntad de participar en la causa de un monumento es un gesto evidente de valoración y de legitimación de un músico. Aunque la relación de Francesc Pujol con Falla se forjó años después del festival -sobre todo con las gestiones del Orfeó Català para estrenar Atlántida ${ }^{48}$ la programación de su nombre es razonable, ya que el músico mantuvo una estrecha relación con la Cobla Barcelona durante la primera etapa de su historia ${ }^{49}$.

Uno de los hechos más sorprendentes del festival fue la petición que hizo Falla respecto a la sardana coreada L'Empordà de Enric Morera. Aunque Falla había relatado en una entrevista que Morera "le interesaba mucho" 50 , no llegó a forjar una relación con el músico ${ }^{51}$.Y es que, incluso en alguna ocasión, Morera criticó la estética de Falla y llegó a calificar al músico de "gitano exangüe" 52 . El diario La Vanguardia publicó el programa del festival y relató que L'Empordà sería interpretada por la cobla, los coros y un esbart. Según el mismo rotativo, "a ruego del maestro Falla" 53 se exhibiría un decorado de Salvador Alarma conocido con el nombre de L'Emporda ${ }^{54}$. Esta petición también se incluyó en el programa de mano: "a ruego del Maestro Falla, acabará la primera parte del Festival con la interpretación de L'Empordà [...], durante la que se exhibirá el magnífico decorado del Maestro Salvador Alarma, pintado para la escenificación de esta obra" ${ }^{25}$. Es muy probable que Falla conociera por la prensa $^{56}$ o por su círculo de amistades el éxito que había tenido la escenificación y la representación en forma de visión plástica de L'Empordà durante el Festival Enric Morera, celebrado unas semanas antes en el Teatro Olympia ${ }^{57}$. Sea como sea, la petición de Falla supuso una clara legitimación: la sardana, una danza de origen popular, se podía poner en relación con los principios de obra

\footnotetext{
${ }^{47}$ Carta de Manuel de Falla a Joan Gisbert, 14-7-1927, Granada, Archivo Manuel de Falla, Correspondencia, top. 7168-034.

${ }^{48}$ Centre de Documentació de l'Orfeó Català, Fondo Francesc Pujol, Manuel de Falla, top. R313, R316, R817.1, R817.2, R817.3.

${ }^{49}$ A. Fontelles-Ramonet: La Cobla Barcelona..., p. 73.

50 "Un diálogo con Manuel de Falla", La Noche, 6-2-1925, p. 1.

${ }^{51} \mathrm{Ni}$ en el Archivo Manuel de Falla ni en la Biblioteca de Catalunya -donde se encuentra el Fondo Enric Morera- se conserva epistolario entre ambos músicos.

${ }^{52}$ Miquel Saperas: El mestre Enric Morera, Barcelona, Socitra, 1969, p. 110.

53 "Grandiós Festival de Música Catalana", La Vanguardia, 17-3-1927, p. 17.

${ }^{54}$ Se refiere a la visión plástica L'Empordà de Salvador Alarma, estrenada el 20 de febrero de 1927 en el Teatro Olympia, durante el Festival Popular Enric Morera.

55 "Festival de música catalana en honor de Manuel de Falla", Granada, Archivo Manuel de Falla, top. 1927_0017. "A prec del Mestre Falla, acabarà la primera part del Festival amb la interpretació de L'Empordà [...], durant la qual serà exhibit el magnífic decorat del Mestre Salvador Alarma, pintat per a l'escenificació d'aquesta obra".

56 "El decorat de L'Empordà", La Veu de Catalunya, Barcelona, 16-2-1927, p. 4; "Festival en honor del Maestro Morera", El Diluvio, Barcelona, 22-2-1927, p. 15; "Homenatge de diumenge passat", La Veu de Catalunya, Barcelona, 23-2-1927, p. 6.

57 "Festival Enric Morera", La Veu de Catalunya, Barcelona, 22-2-1927, p. 5.
} 
de arte total ${ }^{58}$ que enmarcaban el movimiento artístico de los ballets rusos ${ }^{59}$, un género que el compositor ya había cultivado a petición de Serguéi Diáguilev. Y es que la petición de Falla ocasionó que L'Empordà de Morera se convirtiera en un espectáculo audiovisual y escénico que enlazaba tres elementos clave: música, escenografia y coreografia.

A lo largo de los años, Falla prestó especial atención a los géneros de origen popular. El músico se impregnó de particularidades estilísticas provenientes de danzas de las regiones de España y las utilizó, ocasionalmente, para componer ${ }^{60}$.El caso de la jota ${ }^{61}$ lo ejemplifica. Falla utilizó este género en Cuatro piezas españolas - concretamente en la primera, titulada Aragonesa ${ }^{62}$, en Siete canciones populares españolas y en El sombrero de tres picos, donde ${ }^{63}$, además de usarla para caracterizar musicalmente al personaje de la Molinera, la transmutó en forma de leitmotiv hasta la Danza inal $^{64}$. Por lo tanto, todo apunta a que el músico prestó atención al género musical de la escenificación de L'Empordà:la sardana. En cuanto al elemento escenográfico, algunos especialistas, como Jorge de Persia y Ángela García de Paredes, afirman que las impresiones visuales, de percepción de paisajes y entornos, estuvieron muy presentes en la definición de los aspectos musicales a lo largo de la vida de Falla ${ }^{65}$. Según Ana María Arcas el estreno de El sombrero, junto con Picasso y Massine, constituyó un momento de enorme trascendencia en su trayec-

\footnotetext{
${ }^{58}$ Gesamtkunstwerk (en alemán), y su traducción al español "obra de arte total", es un término usado por Richard Wagner al explicar la filosofía de su dramaturgia para referirse a un tipo de obra de arte autónoma que integra de manera simultánea y relacionada diferentes disciplinas artísticas, como la música, el teatro y las artes visuales. El concepto ya había sido desarrollado previamente por otros personajes como Otto Philipp Runge o Caspar David Friederich. Durante el primer tercio del siglo XX, este concepto se utilizó en algunos movimientos artísticos, como los Ballets Rusos, con el objetivo de describir un objeto estético. Mercè Saumell: El Teatre Contemporani, Barcelona, Editorial UOC, 2006; Olivier Schefer: Variations on Totality: Romanticism and the Total Work of Art, Baltimore, Johns Hopkins University Press, 2011; Lourdes Jiménez: El reflejo de Wagner en las artes plásticas españolas. De la Restauración a la Primera Guerra Mundial, tesis doctoral, Universitat de Barcelona, 2013; Teresa Montiel: "Sergei Diághilev, la renovación del Ballet”, ArtyHum. Revista de Artes y Humanidades, 24, 2016, pp. 93-104.

${ }^{59}$ T. Montiel: "Sergei Diághilev...", p. 102.

${ }^{60}$ Manuel García Matos: "El folklore en 'La vida breve' de Manuel de Falla”, Anuario Musical, 26, 1971, pp. 173-197.

${ }^{61}$ Varios autores han hablado de la influencia del género de la jota en la obra de Falla. Manuel García Matos: "Folklore en Falla", Revista trimestral de los conservatorios españoles, 3, 4, 1953, pp. 41-68; Miguel Manzano: La jota como género musical, Madrid, Alpuerto, 1995, p. 432; Tomás Marco: "Falla y la utilización del material tradicional en la composición actual", Manuel de Falla: latinité et universalité. Actes du Colloque International tenu en Sorbonne, 18-21 novembre 1996, Louis Jambou (dir.), París, Université Paris X, 1999, pp. 563-575.

${ }^{62}$ Louis Jambou: "Arquetipos hispanos en la obra de Manuel de Falla", Manuel de Falla: latinité et universalité. Actes du Colloque International tenu en Sorbonne, 18-21 novembre 1996, Louis Jambou (dir.), París, Université Paris X, 1999, p. 8.

${ }^{63}$ Miguel Manzano: "Fuentes populares en la música de 'El sombrero de tres picos', de Manuel de Falla", Nassarre, 9, 1, 1994, pp. 119-144.

${ }^{64}$ L. Jambou: "Arquetipos hispanos...", pp. 7-9.

${ }^{65}$ Jorge de Persia: "Atläntida, a on ets...?", Quodlibet, 55, 2014, pp. 101-131; Ángela García de Paredes: "Atlántida sumergida", Revista Europea de Investigación en Arquitectura, 6, 2016, pp. 58-71.
} 
toria artística, ya que, aparte de haber conseguido crear música de estética española y con dimensión universal, participó en la revolución estética de la escenografia $\mathrm{y}$ del ballet ${ }^{66}$. Con el paso de los años, Falla estableció vínculos con escenógrafos que destacaban en el momento, como Hermenegildo Lanz o Néstor Martín-Fernández $z^{67}$. En Cataluña mantuvo amistad con Oleguer Junyent y Ramon Capmany ${ }^{68}$, dos escenógrafos que en el 1933 diseñaron los decorados de La vida breve y El amor brujo en el Liceu ${ }^{69}$. Por lo tanto, no es de extrañar que Falla, familiarizado con el mundo escenográfico, pidiera la exhibición del lienzo de Salvador Alarma durante la interpretación de la Cobla Barcelona.Aunque no se ha localizado ningún boceto, el cronista de la Revista Orfeó Gracienc lo describió asi: "Aparece la costa brava ampurdanesa en espléndida visión. Sale de la espuma la sirena, que va al encuentro del pastor, el cual desciende de la montaña sin nada en la cabeza, sin duda por respeto a la mitológica hembra de pelo rubio y cola de pez que le espera. Se encuentran en medio de la llanura" ${ }^{\text {"70 }}$.

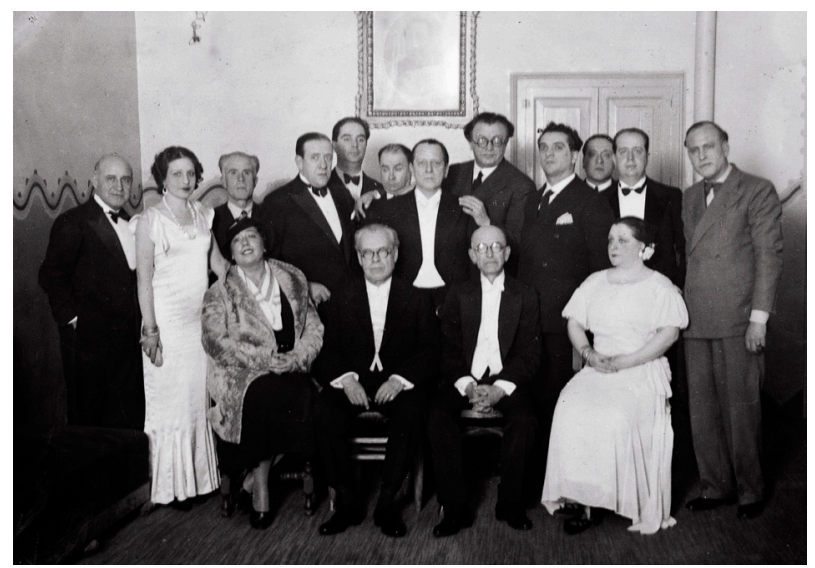

Ilustración 6. Función de honor a Manuel de Falla en el Gran Teatre del Liceu. 2-10-1933.

Sentados: Hina Spani, Joan Lamote de Grignon, Manuel de Falla, Concepció Callao.

De pie: Oleguer Junyent, Sra. Guinmà, Sr. Jordà, Antoni Capdevila, Carlos Morelli, Rafael

Moragas, Frank Marshall, Alfred Padovani, Pau Civil, Miquel Borrull, Ramon de Capmany,

Joaquim Alsina (Fondo Rafael Moragas, Arxiu Fotogràfic de Barcelona)

\footnotetext{
${ }^{66}$ Ana María Arcas: Escenografia en la música de Manuel de Falla: del Amor brujo al Retablo de maese Pedro, tesis doctoral, Sevilla, Universidad de Sevilla, 2017, p. 79.

${ }^{67}$ A. Arcas: Escenografia..., p. 656.

${ }^{68}$ Granada, Archivo Manuel de Falla, Archivo fotográfico, top.7/169 y Epistolario Ramon Capmany, top. 14989

69 "Gran Teatre del Liceu", La Vanguardia, Barcelona, 17-11-1933, p. 4.

70 "Festival Popular Morera", Revista Orfé Gracienc, Barcelona, 20-2-1927. "Apareix la costa brava empordanesa, en esplèndida visió. Surt de l'escuma la sirena, que va a l'encontre del pastor, el qual davalla de la muntanya sense res al cap, sens dubte per respecte a la mitològica fembra de cabells rossos i cua de peix que l'espera. Es troben al bell mig del pla".
} 
Incluso podría ser que los ballets populares que se presentaron en la escenificación de L'Empordà, instrumentados por Antoni Català ${ }^{71}$, fueran bailados ante el lienzo con la misma idea escenográfica, un concepto que el crítico Rafael Giné ya había defendido en 1922 en la revista La Sardana: "No soy partidario de que se baile la sardana sobre los escenarios [...]. En cambio, los ballets catalanes, estos ballets nuestros que tienen un poco de la alocada coreografia rusa y conservan toda la ceremonia y fineza del minué medieval, encuadran perfectamente en el marco del escenario"72. En definitiva, todo hace pensar que Manuel de Falla se sintió atraído por la sardana y los ballets interpretados por la Cobla Barcelona en formato escénico, unos géneros que compartían ciertos vínculos con el movimiento artístico de los ballets rusos.

\section{La sardana según Manuel de Falla}

Aunque Manuel de Falla destinó parte de su tiempo a publicar escritos de temática musical y también dedicados a personalidades de la música ${ }^{73}$, en ninguno de ellos plasmó la opinión respecto a la sardana y la cobla, un género y una formación que, al parecer, tuvo presente a lo largo de su vida. Y es que aparte de escuchar la Cobla Barcelona, el músico coincidió con otras agrupaciones que interpretaban y difundían el género, como La Principal de la Bisbal, durante un verano en Tossa de $\mathrm{Mar}^{74}$, la Orquestra Pau Casals o la Banda Municipal de Barcelona ${ }^{75}$. A pesar de la proposición de la Cobla Barcelona hecha por Josep Juncà en 1926, Falla no llegó a escribir ninguna composición para cobla. Sin embargo, varios documentos conservados en el Archivo Manuel de Falla demuestran que, además de tener curiosidad e interés por la formación y el género, podría haber comenzado a trabajar en un proyecto.

71 "Festival de música catalana en honor de Manuel de Falla", Granada, Archivo Manuel de Falla, top. 1927_0017.

${ }^{72}$ Rafael Giné: "La sardana a l'escenari", La Sardana, mayo 1922, p. 88. "No sóc partidari que es balli la sardana als escenaris [...]. En canvi els ballets populars catalans, aquests ballets nostres que tenen un xic de l'eixelebrada coreografia russa, i serven tota la cerimònia i finesa del minuet medieval, enquadren perfectament en el marc de l'escenari".

${ }^{73}$ De 1916 a 1939, Manuel de Falla publicó escritos en la Revista Musical Hispanoamericana, Enciclopedia abreviada de la música, Revue Musicale, Revista Cruz y Raya, Revista Isla. En 1950, Federico Sopeña publicó una recopilación de los principales textos titulado Escritos sobre música y músicos, Buenos Aires, Espasa Calpe 1950

${ }^{74}$ Granada, Archivo Manuel de Falla, top. R.7919; Centre de Documentació Acadèmia Marshall.

75 "Banda Municipal", La Vanguardia, Barcelona, 25-9-1928, p. 9. El 23 de septiembre de 1928, Falla asistió acompañado de Frank Marshall a un concierto de la Banda Municipal de Barcelona en la plaza Sant Jaume. La formación catalana interpretó por primera vez la transcripción de la sardana Festa Major de Enric Morera, realizada por Joan Lamote de Grignon. 


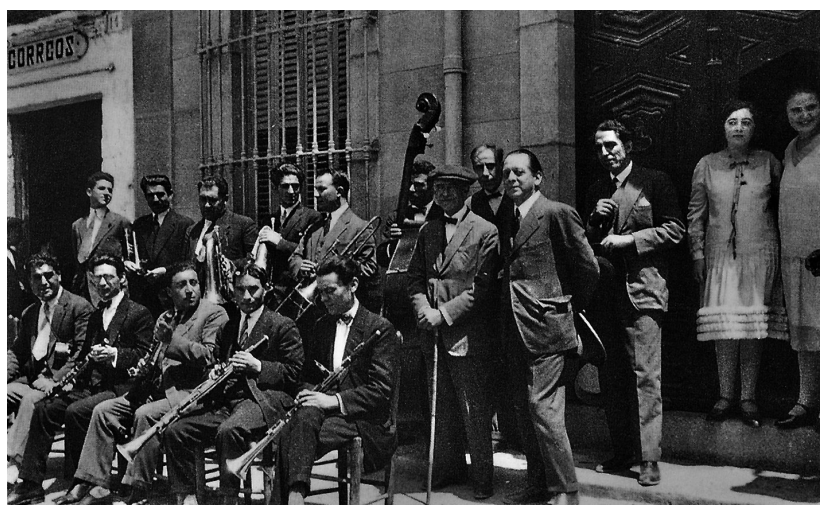

Ilustración 7. Manuel de Falla, Frank Marshall, Jaume Pahissa y la cobla La Principal de la Bisbal en Tossa de Mar, década de 1920. Centre de Documentació Acadèmia Marshall

Joan Baptista Lambert fue uno de los compositores catalanes que mantuvo contacto con Falla durante el primer tercio del siglo XX. Aparte de intercambiarse $\operatorname{cartas}^{76}$, coincidieron en varias ocasiones en Barcelona y en Granada ${ }^{77}$. Falla conservó dos sardanas para cobla de Lambert: El gegant del Pi y L'estiuada $^{78}$. Ambas partituras, realizadas por un copista, están escritas en un papel de 34,5 x 24,5 cm. En la parte inferior consta la marca:"Los Madrazo, 13, Madrid"; y en la parte superior, un logotipo: "Asociación Española de Compositores de Música". El gegant del Pi cuenta con una plantilla de diez intérpretes: flabiol y tamborí, dos tiples, dos tenoras, dos cornetines, dos fiscornos y un contrabajo; mientras que en L'estiuada son once, con la inclusión de un trombón. En las dos piezas, Falla incluyó varias modificaciones de notas y alteraciones con lápiz. También incorporó algunos reguladores de dinámica, ornamentaciones, signos de expresión -ligaduras y acentos-y añadió algunas indicaciones de los instrumentos.

El archivo personal de Lambert, conservado en el Centre de Documentació del Orfeó Català (CEDOC $)^{79}$, conserva partituras manuscritas para piano y otras formaciones de viento de las dos sardanas, pero ninguna de ellas para cobla.A partir de la comparación de las versiones del CEDOC, las conservadas en el Archivo Manuel de Falla y dos versiones localizadas en el archivo de

\footnotetext{
${ }^{76}$ Granada, Archivo Manuel de Falla, Correspondencia, Carpeta Joan Baptista Lambert, top. 7166.

${ }^{77}$ Carta de Manuel de Falla a Joan Baptista Lambert, Granada, Archivo Manuel de Falla, Correspondencia, top. 7166-004.

${ }^{78}$ Granada, Archivo Manuel de Falla, top. R.7919.

${ }^{79}$ Los herederos de Lambert cedieron el archivo personal del compositor al Centre de Documentació de l'Orfeó Català en 1995. En este constan varias versiones para agrupaciones de viento de las dos composiciones, pero ninguna de ellas es para cobla.
} 
Músics per la Cobla de Sabadell ${ }^{80}$, observamos que gran parte de los cambios realizados por el músico andaluz son fruto de errores que hizo el copista durante la copia.Tan sólo algunos cambios de notas, así como otras propuestas de dinámica en determinados pasajes, son propuestas efectuadas por Falla que divergen de los originales de Lambert. Aunque Elena Torres apunta que las diversas indicaciones conservadas en las partituras constatan que Lambert recibió sugerencias, orientaciones y correcciones a la hora de componer o instrumentar estas piezas - una tarea que Falla ya había llevado a cabo con otros compositores catalanes, como Jaume Pahissa, Robert Gerhard o Joaquim Nin-Culmell ${ }^{81}$, , varios factores insinúan que las podía tener simplemente como ejemplo de un determinado género musical. Por un lado, las dos composiciones están escritas en una etapa muy temprana ${ }^{82}$, entre 1906 y 1913 aproximadamente ${ }^{83}$, en la que no se conserva epistolario entre ambos músicos ${ }^{84}$. Por otro lado, y en medio de las partituras, se conserva un borrador titulado "Instrucciones sobre la sardana llarga" 85 . En este documento, Joan Baptista Lambert redactó varias observaciones referentes a la estructura musical del género. A nivel formal, recalcó que la sardana se componía de dos secciones (AB): "La sardana compónese de dos partes, Curts y Llarcs [sic]. El número de compases de Curts o Llarcs es ilimitado. Con todo, es conveniente que los Curts no pasen de 30 y los Llarcs, de 85. Los sardanistas tienen en mucha estima el que las dos partes de la sardana sean impares: v. g. 19-71; 25-69; etc." 86 .

También destacó los principios rítmicos característicos de cada sección y especificó la entidad métrica usual: la combinación del compás binario de subdivisión binaria (2/4) y el compás binario de subdivisión ternaria (6/8). A la vez, recalcó características estilísticas provenientes del canon interpretativo de las coblas: las repeticiones que efectúan durante la interpretación ${ }^{87}$, el

\footnotetext{
${ }^{80}$ Sabadell, Músics per la Cobla, Arxiu general, top. A02214 y A01692

${ }^{81}$ Elena Torres: "Manuel de Falla en la creación...", 2002, p. 73-88.

82 "Sardanes estrenades durant l'hivern", Homenatges als mestres compositors de sardanes, Barcelona, 264-1908, p. 9. Según la publicación, El gegant del Pi se estrenó en 1908.

${ }^{83}$ En 1908 se editó una versión para piano de El Gegant del Pi y, en el mismo año, la cobla La Principal de Perelada la grabó en versión para cobla. En 1914 se editó una versión para piano de L'estiuada. Barcelona, Biblioteca de Catalunya, Fondo Nadal Puig, top. M 4318; Vilassar de Mar, Arxiu Municipal de Vilassar de Mar, Fondo Antoni Torrents, top. 650051; Madrid, Biblioteca Nacional de España, top. MP/2696/18.

${ }^{84}$ Granada, Archivo Manuel de Falla, Epistolario Lambert, top. 7166-001. La carta más temprana entre Lambert y Falla data del 12-11-1926.

${ }^{85}$ Granada, Archivo Manuel de Falla, top. R.7919.

${ }^{86}$ Ibid.

${ }^{87}$ Cuando se interpretan para ser bailadas, las coblas repiten las secciones según la recurrencia. Hoy día, las más generalizadas en los bailes son AABBABB y AABBAABBBB, y en los conciertos AABB.
} 
contrapunto $^{88}$ y el golpe final ${ }^{89}$. En el reverso, anotó la tesitura de los instrumentos de la cobla y su transposición. También incorporó la extensión sonora y el consecuente efecto sonoro de cada instrumento y algunos aspectos relacionados con las tonalidades: "Las sardanas en general se escriben en Fa, Do, $\mathrm{Si}$, Mayores y modulando a sus relativos menores. Se tiene muy en cuenta el no tener gran trato con tonalidades de $\#$ [sostenidos]. El fluviol solo puede ejecutar en Do, Sol, Fa (de su instrumento) por ser dificil con accidentales"

Así pues, podría ser que Falla -a falta de un tratado de instrumentación para cobla- guardara estos documentos con la voluntad de componer una obra. Incluso podría ser que el estreno de las cuatro sardanas de su amigo Amadeu Vives durante el concierto-homenaje dedicado a Vives en el Teatro Olympia en 1926 por la Cobla Barcelona -un evento que suscitó una gran expectación ${ }^{91}$-, hubiera sido su principal motivación, reforzada por la petición de la misma cobla con la intercesión de Moragas como intermediario. Sea como sea, el concierto-homenaje a Falla organizado por Concerts Blaus y celebrado unos meses más tarde en el mismo teatro no incluyó ninguna sardana compuesta por Falla.

Aunque la petición que hizo la Cobla Barcelona incluía la elección de una composición en forma de glosa o bien de sardana, algunas declaraciones del músico andaluz dan a entender que el género de la glosa ${ }^{92}$ no habría terminado de encajar en los principios estéticos del compositor. En este sentido, Falla se alejó de algunos ideales promovidos por Felip Pedrell, como, por ejemplo, la utilización textual del documento popular ${ }^{93}$.Y es que en 1915 Falla afirmó: "Únicamente disiento de mi maestro en lo que respecta al uso de los cantos populares. Él cree que deben usarse como son.Yo, que solo pueden servir de base para la inspiración y no tomarlos y armonizarlos" ${ }^{4}$. Así lo confirmó el compositor en varios escritos y entrevistas de 1917, 1920, 1923 y $1925^{95}$, e incluso lo relató en una carta dirigida a Joan Llongueras:

\footnotetext{
${ }^{88}$ Entre las diferentes secciones y como señal de intervalos de descanso, el flabiolaire interpreta una breve frase musical conocida con el nombre de "contrapunt" que se interpreta en el tono en que termina B.

${ }^{89}$ Para finalizar, todos los instrumentistas efectúan el "golpe final", que consiste en la repetición de la última nota escrita con un acuerdo tutti, con sequedad y con valor de corchea en el siguiente tiempo del compás.

${ }^{90}$ Granada, Archivo Manuel de Falla, top. R.7919.

91 "Concert-Homenatge Amadeu Vives", La Veu de Catalunya, Barcelona, 13-7-1926, p. 4.

${ }^{92}$ Una glosa es una composición musical de forma libre, casi siempre de un solo movimiento, centrada en una melodía popular que se transforma y se desarrolla mediante repeticiones, variaciones, ampliaciones, modulaciones, cambios de instrumentación y otros recursos de escritura. Albert Fontelles-Ramonet, Joaquim Rabaseda: "El ball de gegants de Solsona i la invenció d'un gènere musical", Oppidum: Revista Cultural del Solsonès, 16, 2018, pp. 86-101.

${ }^{93}$ Yvan Nommick: "El influjo de Felip Pedrell en la obra y en el pensamiento de Manuel de Falla", Recerca Musicològica, 14-15, 2004, p. 292.

94 Tomás Borrás: "Los músicos nuevos. El maestro Manuel de Falla", Por esos mundos, Madrid, 16-31915, p. 269.

${ }^{95}$ Y. Nommick: "El influjo de Felip Pedrell...", p. 292.
} 
Empleo muy raramente (sino en casos muy justificados) el documento auténtico popular. Es más: procuro no servirme de él más por como complemento indispensable a mis estudios directos de la música del pueblo [...]. Mi intento no es otro que el de extraer (¡y cuán laboriosamente!) la sustancia escondida en la música natural para procurar convertirla en música de $\operatorname{arte}^{96}$.

En 1929, la dramaturga Mary Hoyt Wiborg, que escribía en la revista Art et Décoration y que ya había coincidido con Falla en Granada ${ }^{97}$, pidió al músico que le enviara unas sardanas. El 14 de diciembre de 1929, Falla se dirigió a Joan Llongueras: "voy a pedirle un favor: títulos y autores de 8 o 10 sardanas (publicadas para piano) entre las mejores y más características" 98 .Al no recibir respuesta, Falla se dirigió a Gisbert: “Telefoneé al Sr. Llongueras rogándole le diga títulos y autores de ocho o diez sardanas elegidas entre las mejores y más características [...] adquiera los ejemplares y los remita a Mary Wiborg" "E9 . El día 26 del mismo mes, Falla se dirigió a Wiborg: "Hago que os envíen desde Barcelona una pequeña colección de sardanas, que sé que os gustan mucho. Han sido escogidas entre las más características" ${ }^{100}$. Aunque no conocemos el nombre de las sardanas ni el motivo por el que fueron requeridas ${ }^{101}$, es obvio que Wiborg sabía que Falla era conocedor del género. Incluso sería del todo probable que los dos personajes hubieran hablado previamente de algunos aspectos referentes a la danza.

La sardana fue un género musical que Manuel de Falla tuvo presente hasta el final de su vida. Desde Argentina, espoleó a Jaume Pahissa a escribir una. El día 25 de mayo de 1940, desde Villa Carlos Paz, Falla envió una carta al compositor catalán: "¿Por qué no hace usted un scherzo sinfónico del tipo del Apprenti sorcier basado en la sustancia de algo popular en fuerte carácter rítmico y formal? Una sardana, por ejemplo. Sería para mí una alegría estrenarlo en algún concierto"102. El contenido de esta carta nos permite aproximarnos al pensamiento del compositor. Así es. Falla concibió la sardana como un tipo de composición basada en la sustancia de lo popular, una obra de carácter rítmico y formal bastante pronunciada. Aunque Jaume Pahissa no llegó a componerla, años más tarde, concretamente el 12 de marzo de 1944, Falla continuó

\footnotetext{
${ }^{96}$ Carta de Manuel de Falla a Joan Llongueras, 21-1-1927, Granada, Archivo Manuel de Falla, Correspondencia, top. 7224 .

${ }^{97}$ Granada, Archivo Manuel de Falla, Epistolario Mary Wiborg, top. 7780. En agosto de 1929, Wiborg visitó a Falla en Granada.

${ }^{98}$ Granada, Archivo Manuel de Falla, Epistolario Manuel de Falla a Joan Llongueras, 14-12-1929, top. 7224-019.

${ }^{99}$ Ibid., Epistolario Manuel de Falla a Joan Gisbert, 25-12-1929, top. 7050-051(1).

100 Ibid., Epistolario Manuel de Falla a Mary Wiborg, 26-12-1929, top. 7780-049(1). "Je vous fais envoyer de Barcelone une petite collection de Sardanas, que je sais combien vous aimez. Elles sont choisies parmi les plus caractéristiques".

${ }^{101}$ El archivo personal de Wiborg, llamado Mary Hoyt Wiborg Papers, conservado en Yale, The Beinecke Library, no contiene ninguna carta de Manuel de Falla.

102 Biblioteca de Catalunya, Fondo Jaume Pahissa, Correspondència amb Manuel de Falla, top. M7086.
} 
insistiendo en la materialización de este proyecto: “¿Llegó usted a hacer aquel scherzo-sardana que le sugerí en una ocasión? ¡Lástima que esos trabajos, no siempre gratos, de que usted me hablaba en su carta anterior, le quiten el tiempo para dedicarse a su propia música!"'103.

Todo hace pensar que Manuel de Falla no llegó a componer ninguna sardana ni ninguna obra para cobla. Sin embargo, podría haber tenido la voluntad de incorporar la sonoridad de algunos de sus instrumentos en Atlántida. Al menos, así lo relató José Subirá ante representantes del gobierno y de críticos musicales en un parlamento efectuado en abril de 1932 en el Ateneo de Madrid, antes de un concierto de la Cobla Barcelona ${ }^{104}$ : "La Banda Municipal de Barcelona ha incluido en su plantilla 'tiples' y 'tenoras'. Algunos compositores catalanes los llevan, como instrumentos obligados, a sus producciones sinfónicas.Y esto mismo hace ahora Falla en la composición a que se halla entregado, tomando como base el poema Atlántida" ${ }^{105}$. Así pues: ¿puede ser cierto que Falla quisiera incorporar los instrumentos de la cobla en Atlántida?

\section{Atlántida}

En 1926, Joan Gisbert acompañó a Manuel de Falla al festival de la Sociedad Internacional de Música Contemporánea de Zurich. Durante el viaje de vuelta, el compositor expuso que tenía mucho interés en componer una obra para Cataluña:

Falla tenía un enorme interés en hacer algo para Cataluña, a la que quería muchísimo, por las continuas demostraciones de afecto y cariño que había recibido en Barcelona, pues, aunque el maestro Pedrell le había indicado que hiciera una ópera sobre la vida de Raimundo Lulio [Ramon Llull], esto no entraba en su forma de ser, porque la vida de este fue algo irregular en sus principios. Entonces fue cuando le insinué La Atlántida [...]. Transcurridos unos cuatro meses fuimos a París. Cuando estábamos comiendo en un restaurante, juntamente con el maestro Marshall, Falla nos dijo que ya tenía principiada Atlántida ${ }^{106}$.

Un año más tarde, en 1927, se conmemoró el quincuagésimo aniversario de L'Atlàntida de Mn. Jacint Verdaguer. Alrededor de esa efeméride, se reeditó la obra $^{107}$, se publicaron varios escritos en la prensa ${ }^{108}$ y se organizaron actos

103 Ibid.

104 "Programa Concierto de música catalana a cargo de la Cobla Barcelona, 13-IV-1932", Centre de Documentació de l'Orfeó Català, Fondo Francesc Pujol, top. R432.

105 José Subirá: "Las coblas ampurdanesas", La Sardana, Barcelona, junio 1932, pp. 146-149.

106 "Origen de La Atlántida de don Manuel de Falla", ABC, Madrid, 29-12-1960, pp. 39-43.

${ }^{107}$ En el año 1927, por iniciativa de la Reial Acadèmia de les Bones Lletres y el Consistori dels Jocs Florals, bajo el patronato de la Diputación Provincial de Barcelona, publicaron la edición del cincuentenario de La Atlàntida. Jacint Verdaguer: L’Atlàntida, Barcelona, Estampa de la Casa Miquel-Rius, 1929.

108 "El cincuentenario de la 'Atlántida", La Nación, Madrid, 25-3-1927, p. 6; "Mossen Jacinto Verdaguer", La Correspondencia militar, Madrid, 6-4-1927, p. 1; "Dos Cincuentenarios", La Voz, Madrid, 16-41927, p. 1; "Los juegos florales de La Atlántida", El Sol, Madrid, 6-5-1927. 
conmemorativos $^{109}$. Años más tarde, en una entrevista efectuada por un columnista del diario Ahora, Falla confesó que esta temática había estado presente desde su infancia:"La Atlántida existía en mí desde la infancia. En Cádiz, donde nací, se me ofrecía el Atlántico a través de las columnas de Hércules abriendo en mi imaginación el más bello jardín de las Hespérides" ${ }^{110}$. No es extraño que la proposición de Gisbert, junto con la visión idealizada y melancólica del compositor, se convirtiera en un factor decisivo para seleccionarla.

En marzo de 1927 y tras una recepción de honor en el Ateneu Barcelonès, Falla expuso nuevamente su voluntad de dedicar una composición a Barcelona ${ }^{111}$ : "Yo debo hacer algo que refleje mi reconocimiento por Barcelona. Ínterin llegue este momento, disponed en absoluto de mí, puesto que mucho a los barceloneses debo"112. Y así fue. Con un proyecto inicial de un posible estreno en la Exposición Iberoamericana de Sevilla ${ }^{113}$, y en la Exposición Internacional de Barcelona de 1929 con el Orfeó Català ${ }^{114}$, los trabajos se fueron dilatando y la obra cambió su rumbo, mientras la sociedad española pasaba por la Segunda República y finalmente por la Guerra Civil ${ }^{115}$. Falla se consagró a la obra durante los últimos veinte años de su vida, desde 1926 hasta $1946^{116}$, un período en el que, aparte de verse sacudido por los acontecimientos históricos que ocurrieron en España y que le afectaron -como la quema de iglesias ${ }^{117}$ o la muerte de Federico García Lorca ${ }^{118}$-, sufrió varios problemas de salud que le obligaron a dejarla temporalmente aparcada ${ }^{119}$.

\footnotetext{
109 "Homenaje a Verdaguer", ABC, Madrid, 14-6-1927, p. 23.

110 "El maestro Falla está instrumentando La Atlántida de Verdaguer", Ahora. Diario Gráfico, Madrid, 25-11-1931, p. 22.

${ }^{111}$ Loreto Busquets: "El mito de Atlántida: de Verdaguer a Falla y Halffter", Studi Ispanici, 2006, p. 167. Busquets destaca que Atlántida es un "homenaje a Cataluña y en particular a Barcelona, recordada por el propio Falla en la dedicatoria de su obra, y homenaje al poeta y a la nación que representa".

112 "En el Ateneu Barcelonès", La Noche, Barcelona, 23-3-1927, p. 3.

${ }^{113}$ Finalment, el Orfeó Català y la Cobla Barcelona participaron en este evento. Olimpia García López: "Los conciertos en la Exposición Iberoamericana de Sevilla (1929-1930): un acercamiento a través de la prensa", Imagen, escenografía y espectáculo en la Exposición Iberoamericana: testimonios, artistas y manifestaciones, Sevilla, Editorial Universidad de Sevilla, 2018, pp. 155-182.

${ }^{114}$ En el archivo de Francesc Pujol, conservado en el CEDOC, constan varias cartas entre Pujol y Falla, entre las cuales hay una, con fecha de 28 de agosto de 1929, en que Pujol, a petición de Falla, desglosa un presupuesto de 65340 pesetas para el viaje y la estancia de diez días en Sevilla para estrenar La Atlántida durante la Exposición Iberoamericana. Centre de Documentació de l'Orfeó Català, Fondo Francesc Pujol, top. R316.

115 Jorge de Persia: Atlántida, a on ets...?", pp. 101.

${ }^{116}$ Andrew Budwig: Manuel de Falla's Atlántida: an historical and analytical study, tesis doctoral, Chicago, University of Chicago, 1984, p. 2.

${ }^{117}$ Eckhard Weber: "Colón-El Cristoforus. Manuel de Falla, la Guerra civil y su cantanta escénica Atlántida", Quodlibet, 55, 2014, p. 141.

${ }^{118}$ Louis Jambou: "Arquetipos...", pp. 25-30; Stéphan Etcharry, "Atlántida ou le testament inachevé de Manuel de Falla", comunicación presentada en el coloquio internacional "La musique et l'ultime: esthétique des dernières œuvres" (Évry, Université d'Évry-Val-d'Essonne, 8-9 décembre 2015), editado y publicado en línea en 2018, p. 6, https://univ-reims.academia.edu/ETCHARRYStéphan (consulta 20-8-2021).

${ }^{119}$ Victòria Llort Llopart: "La emoción estética en Atlântida de Manuel de Falla: horror, exaltación y religiosidad", Iberic@l. Revue d'Études Ibériques et Ibéro-Américaines, 2014, pp. 77-88.
} 
Los manuscritos de Atlántida le acompañaron por Cádiz, Granada, Mallorca, Barcelona y finalmente Argentina, donde vivió desde 1939 hasta 1946. Durante veinte años, el compositor modificó y amplió algunos aspectos: reestructuró partes del texto de Verdaguer ${ }^{120}$, incorporó textos externos ${ }^{121}$, agrandó la estructura $^{122}$, de dos a tres partes con la inclusión de un prólogo ${ }^{123}$, y, según Yvan Nommick, terminó concibiendo la obra como una "síntesis mitológica, legendaria, histórica, religiosa y musical de los hispanos" ${ }^{24}$. La idea de transmitir un "compendio del mundo antiguo y el mundo moderno"125 llevó a Falla a realizar una extensa labor de investigación y de documentación sobre la música griega $^{126}$, la música de la India, la música popular italiana, la catalana, la bizantina, la oriental japonesa, la china, la de los incas y también la música medieval ${ }^{127}$. Incluso, para comprender a la perfección el texto de Verdaguer, estudió lengua catalana a partir de varios libros ${ }^{128}$ que compró en Barcelona y otros que recibió de Joan Gisbert ${ }^{129}$.

Cuando Falla murió, dejó doscientas dos hojas que contenían bocetos y borradores en diferentes estados de finalización ${ }^{130}$. Poco después del entierro en la Catedral de Cádiz, la diplomacia española las entregó a Germán de Falla, hermano del compositor ${ }^{131}$. Años más tarde, Ernesto Halffter y Ricordi

${ }^{120}$ Jean-Charles Hoffelé: Manuel de Falla, Paris, Fayard, 1992, pp. 347-350; L. Busquets: "El mito...", pp. 157-189.

${ }^{121}$ Eckhard Weber: "Atlántida' de Manuel de Falla: nuevas soluciones para el teatro musical", Anuari Verdaguer, 11, 2003, p. 640.

122 Marie-Claire Zimmermann: "L'Atlàntida: poème en langue catalane revisité par Manuel de Falla", Manuel de Falla: latinité et universalité. Actes du Colloque International tenu en Sorbonne, 18-21 novembre 1996, Louis Jambou (dir.), París, Université Paris X, 1999, pp. 115.

${ }^{123}$ J. de Persia: "Atlántida, a on ets...?", pp. 107.

${ }^{124}$ Yvan Nommick: "Lévolution des effectifs instrumentaux dans l'œuvre de Manuel de Falla: continuité ou discontinuité", Manuel de Falla: latinité et universalité. Actes du Colloque International tenu en Sorbonne, 18-21 novembre 1996, Louis Jambou (dir.), París, Université Paris X, 1999, p. 333. "Une synthèse mythologique, historique, religieuse et musicale de l'hispanité".

${ }^{125}$ Yvan Nommick: "La herencia de la música y el pensamiento de Manuel de Falla en la posguerra (1940-1960)", Actas del congreso "Dos décadas de cultura artística en el Franquismo (1936-1956)", Ignacio de Henares Cuéllar, María Isabel Cabrera García, Gemma Pérez Zalduondo, José Castillo Ruiz (dirs.), Granada, Universidad de Granada, 2001, p. 29.

${ }^{126}$ Andrew Budwig: "Una metodología para el estudio de la Atlántida de Manuel de Falla", Revista de Musicología, 1, 1982, pp. 3-4.

${ }^{127}$ Yvan Nommick: "L'Atlantide de Manuel de Falla: du mythe platonicien à la bibliothèque mythique", Pensée mythique et création musicale, Marie-Pierre Lassus (ed.), Lille, Université Charles de Gaulle, 2006, pp. 179-191.

${ }^{128}$ Actualmente los libros se conservan en el Archivo Manuel de Falla.

129 Granada, Archivo Manuel de Falla, Epistolario Joan Gisbert a Manuel de Falla, 7-4-1932, top. 7049-038: "Por este mismo correo y certificado le remito la Gramática Catalana, aunque no es la edición Salvat me han dicho es absolutamente igual, habiéndome determinado a remitírsela pues tal como la piden no se encuentra".

${ }^{130}$ A. Budwig: Manuel de Falla's..., p. 1.

${ }^{131}$ Suzanne Demarquez: Manuel de Falla, París, Flammarion, 1963, p. 200. 
suscribieron un contrato para revisar y completar Atlántida ${ }^{132}$. La obra se estrenó en el Gran Teatre del Liceu el día 24 de noviembre de 1961, con la dirección de Eduard Toldrà ${ }^{133}$. En plenas vísperas del estreno, Xavier Montsalvatge publicó una crónica en La Vanguardia: “¿Es esta Atlántida el testamento catalán de Manuel de Falla? [...], todo hace suponer que en ella la intervención de Halffter habrá sido mínima y, en todo caso, lo suficientemente hábil para no ponerse en evidencia" ${ }^{134}$. Jaume Pahissa ${ }^{135}$ se mostró muy crítico con el estreno: "En la partitura de Atlántida no hay casi nada de Falla.El Maestro estaba muy agotado en los últimos años y no pudo ni siquiera esbozarla. Por otra parte, no se ajusta a su estilo y forma de sentir la música. No desmerece su calidad, que la tiene, pero le falta el nervio y la profundidad que exige el poema épico" 136 .

Durante los años posteriores, Ernesto Halffter continuó trabajando en la obra y en 1976 estrenó una nueva versión conocida con el apodo de "versión de Lucerna" "137. En esta, Halffter excluyó buena parte de la música de invención propia y fijó en seis las secciones de la segunda parte, una decisión que, según el director Edmon Colomer "otorgó a la obra el equilibrio formal que necesitaba" ${ }^{138}$. Así lo relató Halffter: "He procurado terminar La Atlántida tal y como lo hubiera hecho Manuel de Falla. En la nueva versión he revisado toda la orquestación. Es una labor que me ha costado años de trabajo y que ya no pienso retocar" 139 .

A lo largo de los años, Atlántida ha estado rodeada de dudas. Más allá de los escritos pioneros de Jaume Pahissa, Suzanne Demarquez, Federico Sopeña, Enrique Franco y Antonio Gallego, cabe citar los trabajos más recientes de Yvan Nommick, Michael Christoforidis ${ }^{140}$, Carol Hess, Andrew Budwig, Stéphan Etcharry, Loreto Busquets, Verónica Llort, Jorge de Persia y Eckhard Weber, que han hecho posible avanzar en la comprensión de la obra. Suzanne Demarquez fue una de las primeras en intentar averiguar qué partes habían

${ }^{132}$ S. Etcharry: "Atlántida ou le testament...", p. 13; Consuelo Carredano: "Devociones ejemplares: algunas pautas en la relación de Manuel de Falla y Ernesto Halffter", Cuadernos de Música Iberoamericana, 11, 2006, p. 48.

133 "Estreno mundial de Atlántida", La Vanguardia, Barcelona, 25-11-1961, p. 1.

${ }^{134}$ Xavier Montsalvatge: "Anticipo de Atlántida”, La Vanguardia, Barcelona, 24-11-1961, p. 7.

135 Xosé Aviñoa: Jaume Pahissa, un estudi biogràfic i critic, Barcelona, Biblioteca de Catalunya, 1996, p. 240.

${ }^{136}$ Jaume Pahissa: "La Atlántida", El Noticiero Universal, 20-11-1961. "A la partitura de Atlántida no hi ha gairebé res de Falla. El Mestre estava molt esgotat en els darrers anys i no va poder ni tan sols esbossar-la. D’altra banda, no s'ajusta al seu estil i manera de sentir la música. No desmereixo la seva qualitat, que en té, però li manca el nervi i la profunditat que exigeix el poema èpic".

137 "La versión definitiva de Atlántida", ABC, Madrid, 10-9-1976, p. 35.

${ }^{138}$ Edmon Colomer: notas al disco Manuel de Falla: Atlàntida [CD], Joven Orquesta Nacional de España, Edmon Colomer (dir.), Auvidis Valois, 1993. V4685, p. 17.

139 "La versión definitiva de Atlántida", ABC, Madrid, 10-1-1976, p. 35.

${ }^{140}$ Michael Christoforidis: Manuel de Falla, Madrid, Fundación Autor, 1998. 
quedado completadas antes de la muerte de Falla ${ }^{141}$. Años más tarde, Andrew Budwig fue uno de los que aportó más información sobre este tema con una tesis doctoral defendida en la Universidad de Chicago en 1984 en la que sugirió una revisión de la edición de Atlántida de Halffter de $1961^{142}$.

Nommick evidenció que el único fragmento completamente orquestado por Falla era el Prólogo, exceptuando algunos compases de Hymnus Hispanicus $^{143}$. A la vez, expuso que la primera parte estaba bastante avanzada pero no orquestada; la segunda parte contenía algunos bocetos parciales y numerosas notas de trabajo; y la tercera, borradores con varias indicaciones de instrumentación. José Vallejo concluyó que Halffter había introducido en la segunda parte algunos números de creación personal y espoleó a los musicólogos a estudiar los manuscritos: "las esencias siguen estando en los manuscritos y en las diversas partes con orquestación y realización definitiva" ${ }^{144}$.Y es que, según parece, incluso Halffter tenía sus dudas. En una entrevista de 1961 afirmó que Falla había dejado "más del setenta y cinco por ciento de la obra terminada"145, mientras que el año siguiente hablaba de "unos manuscritos apenas esbozados”146. ¿Puede ser cierto, pues, que Falla incluyera los instrumentos de la cobla en los manuscritos y Halffter los obviara?

\section{Tres indicios}

A mediados del año 1931, pocos días después de la proclamación de la Segunda República española, José María Sert ofreció a Falla una estancia veraniega de dos semanas en la Costa Brava, donde Sert disponía de una casa de verano: "Podríamos aprovechar para visitar Poblet y ponernos de acuerdo con Millet, también dibujar juntos los cristales para las proyecciones y dejar así preparada la representación solemne del próximo año" 147 . Falla, con la idea de un viaje a París y Londres ${ }^{148}$, rechazó la oferta y pospuso la visita. El 24 de octubre de 1931 el compositor exclamaba a Manuel Clausells: “¡Ojalá pueda yo ir a Barcelona, tengo muchos deseos de hallarme de nuevo entre ustedes!" 149. $\mathrm{Al}$ cabo de un mes, la prensa catalana informaba que Manuel de Falla se encontraba en Barcelona y que estaba realizando los últimos retoques de Atlántida. Así

\footnotetext{
${ }^{141}$ S. Demarquez: Manuel de Falla..., p. 204.

${ }^{142}$ A. Budwig: Manuel de Falla's..., p. 39.

${ }^{143}$ Y. Nommick: "LAtlantide...", pp. 171-174.

${ }^{144} \mathrm{~J}$. Vallejo: Atlántida, sonido,..., p. 13.

${ }^{145}$ Ritmo, Madrid, 1961, 316, pp. 12-13.

${ }^{146}$ Intervista con Ernest Halffter [sic], a cura di Giovani Ugolini, en "Programa di sala" del estreno, Milán, Teatro alla Scala, 1962, p. 685. "un manoscritto appena abbozzato".

147 Granada, Archivo Manuel de Falla, Epistolario Josep Maria Sert a Manuel de Falla, 5-1931, top. 7619-1-023.

${ }^{148}$ Ibid., Epistolario Manuel de Falla a Josep Maria Sert, 4-6-1931, top. 7619-1-024.

${ }^{149}$ Ibid., Epistolario Manuel de Falla a Manuel Clausells, 24-10-1931, top. 6843-066.
} 
lo anunció el diario La Humanidad:"El prestigioso músico [...], que se encuentra en Barcelona, [...] está dando los últimos toques a la ópera del glorioso Verdaguer" 150 .

A pesar de disponer de poca información, sabemos que coincidió con Amadeu Vives y con Miquel Llobet ${ }^{151}$, el cual dejó una carta en el Hotel Palace que incluía la pregunta: “¿Qué tal la excursión de hoy?”"152. Es probable que Falla y Sert hubieran visitado el monasterio de Poblet. Juan Viniegra expuso que, durante esta estancia, Falla interpretó varios fragmentos de Atlántida a Gisbert y a Sert y también mostró algunas partituras a Llúis Millet ${ }^{153}$. Durante su estadía, el compositor asistió a un ensayo de la Banda Municipal de Barcelona que entonces estaba preparando un programa que incluía "Danza de fallaires" de Canigó de Jaume Pahissa ${ }^{154}$. Al entrar en el Palau de Belles Arts, Falla se encontró con un periodista y le expuso que había venido para estudiar las características sonoras de los instrumentos de la cobla ${ }^{155}$. Así lo relató el cronista, bajo las siglas J. D. B., en el diario Ahora:

Lamote acoge entusiasmado el interés de Falla por estudiar las características de sonoridad de los instrumentos de viento populares, que, en Cataluña, como se sabe, tienen su más adecuado ambiente en las "coblas" de sardanas [...].-Es la obra [dice Falla] en que mayor entusiasmo he puesto. Quisiera tener salud y vida no solo para terminar La Atlántida sino para crear muchas obras más que, como las anteriores del maestro, sigan marcando en todo el mundo el minuto álgido de la "hora española". Necesitaré un buen año de trabajo para terminarla. Será una obra bastante compleja que llenará todo un programa de concierto. Habrá solistas vocales que representarán el texto dramático del poema, coros y orquesta $[\ldots]$. Me gustaría que se estrenara en Barcelona, con el Orfeó Catalá y la Orquesta Pau Casals ${ }^{156}$.

Según el cronista, la banda interpretó obras en las que se utilizaba la sonoridad de los instrumentos populares: "Escuchó atento las demostraciones que los solistas le hacían con los instrumentos y solicitó la realización de las

150 "Manuel de Falla i l'Atlàntida", La Humanitat, Barcelona, 27-11-1931, p. 6. "El prestigiós músic que es troba a Barcelona, ciutat de la que ha fet un gran elogi, està donant els darrers tocs a l'òpera del gloriós Verdaguer".

${ }^{151}$ Granada, Archivo Manuel de Falla, Epistolario Miquel Llobet a Manuel de Falla, 11-1931, top. 7223-037.

152 Ibid., Epistolario Miquel Llobet a Manuel de Falla, 11-1931, top. 7223-037.

153 Juan Viniegra: Vida intima de Manuel de Falla, Cádiz, Diputación de Cádiz, 1966, pp. 253-267.

154 "Concert de la Banda Municipal", La Publicitat, Barcelona, 28-11-1931, p. 3.

155 "El maestro Falla está instrumentando 'La Atlántida' de Verdaguer", Ahora. Diario Gráfico, Madrid, 25-11-1931, p. 22, http://hemerotecadigital.bne.es/issue.vm?id=0029984357\&search=\&lang=es (consulta 30-8-2021). El artículo incluye un fotomontaje con fotos de Badosa que superpone imágenes de la Banda Municipal de Barcelona en el escenario del Palau de Belles Arts, de intérpretes de tenora, tiple y "barítono" de la misma familia instrumental y una foto de Falla con Joan Lamote de Grignon y el crítico musical Luis Góngora.

${ }^{156}$ Ibid. 
posibilidades sonoras de cada uno de ellos y también los resultados de la fusión de todos" $" 157$. El cronista utilizó palabras de Joan Lamote de Grignon para completar la crónica:

Yo he querido elevar la categoría estética de las "chirimías" parientes directos de la gaita, que en Cataluña se llama "sac de gemecs" [dice Lamote de Grignon]. Lo mismo hice con la "dulzaina" valenciana, aplicando a la tenora y al tiple los progresos de la técnica instrumental para facilitarles la ejecución de determinados pasajes, pero sin atribuirles posibilidades de virtuosismo. Completé, además, la familia de las chirimías, creando el "barítono" y "el bajo" este último se está construyendo- para tener completo el ámbito de sonoridad de esta familia instrumental ${ }^{158}$.

Así pues, la crónica de este diario se convierte en un primer indicio que permite plantear la hipótesis de que Falla tenía la intención de incorporar la sonoridad de los instrumentos de la cobla en Atlántida. Durante la década de 1920, varios compositores catalanes velaron por la fusión de géneros y de timbres en las agrupaciones orquestales. Uno de ellos fue Juli Garreta ${ }^{159}$, que en 1920 estrenó la versión para orquesta sinfónica de Nydia y Maria, dos sardanas que requerían la incorporación de un flabiol y dos tenoras en la plantilla de la orquesta ${ }^{160}$. Otro fue Joan Lamote de Grignon, que en 1921 decidió incluir dos tenoras y un tiple a la plantilla de la banda con el objetivo de ampliar la paleta de colores y, consecuentemente, lograr un timbre especial en determinados pasajes ${ }^{161}$.Aparte de las transcripciones para banda y orquesta de las sardanas, Lamote de Grignon y otros músicos incluyeron la sonoridad de estos instrumentos en obras originales y también en transcripciones de obras de compositores europeos, como, por ejemplo, en la Cabalgata de las valquirias de Wagner o la obertura de Francesca da Rimini de Chaikovski ${ }^{162}$. En 1925, Falla pudo conocer y escuchar esta peculiaridad tímbrica en la plaza del Rei de Barcelona, donde se interpretaron obras que incluían esta sonoridad, como L'Apprenti sorcier de Dukas y Tannhäuser de Wagner ${ }^{163}$.También lo presenció en el homenaje que se le ofreció en el Teatro Olympia en 1927, donde se interpretó La filadora de Joan Lamote de Grignon y Triana de Isaac

\footnotetext{
${ }^{157} \mathrm{Ibid}$.

${ }^{158} \mathrm{Ibid}$.

${ }^{159}$ Barcelona, Centre de Documentació de l'Orfeó Català, Colección de programas de concierto de l'Orfeó Català, "Dissetè concert de l'Associació d'Amics de la Música, 18-6-1920", http://mdc.csuc.cat/ $\mathrm{cdm} / \mathrm{search} /$ collection/ProgPMC (consulta 5-2-2021).

${ }^{160}$ A. Fontelles-Ramonet: "La sardana segons Joaquín Turina", p. 264-265.

${ }^{161}$ Josep Maria Almacellas: Banda Municipal de Barcelona: 1886-1944: del carrer a la sala de concerts, Barcelona, Arxiu Municipal de Barcelona, 2006, p. 243; Rosa Maria Rodríguez: Més enllà de la cobla: el repertori per a tenora en formacions simfòniques, trabajo final de grado, Barcelona, Escola Superior de Música de Catalunya, 2019, p. 27.

162 "Francesca da Rimini de Chaikovski, partitura para banda", Barcelona, L'Auditori, Arxiu de la Banda Municipal de Barcelona.

163 "Falla i la Banda Municipal", La Veu de Catalunya, Barcelona, 9-2-1925, p. 2.
} 
Albéniz ${ }^{164}$, único movimiento de la suite Iberia que incluye esta sonoridad ${ }^{165}$. También sería posible que Falla, que había legitimado a Garreta, hubiera escuchado la Suite empordanesa, una obra para orquesta sinfónica que incorporaba un flabiol y dos tenoras en la plantilla. Incluso sería posible que conociera la obra escénica que había estrenado su amigo Lambert en enero de 1931: Flors de Mar Bella en el Teatre Nou de Barcelona ${ }^{166}$, una composición para orquesta sinfónica que incorporaba una tenora ${ }^{167}$.

Un segundo indicio lo encontramos unos meses después. Entre el 12 y el 15 de abril de 1932, la Cobla Barcelona, invitada por la comisión de fiestas del primer aniversario de la proclamación de la República Española, participó en diferentes actos oficiales ${ }^{168}$, entre los que destaca un concierto de música catalana en el Ateneo de Madrid ${ }^{169}$. Este evento, que se celebró el 14 de abril, contó con una conferencia introductoria de José Subirá, el cual, aparte de glosar la historia de la sardana y de la cobla, remarcó que algunos compositores como Manuel de Falla incluían la sonoridad de los instrumentos en sus obras sinfónicas:

La Banda Municipal de Barcelona ha incluido en su plantilla "tiples" y "tenoras". Algunos compositores catalanes los llevan como instrumentos obligados a sus producciones sinfónicas.Y esto mismo hace ahora Falla en la vasta composición a que se halla entregado, tomando como base el poema La Atlántida, del vate catalán Jacinto Verdaguer ${ }^{170}$.

Aunque Falla y Subirá formaban parte del "Comité para la difusión de los Estudios Musicales mediante el 'Duo Art'" de la Fundación The Aeolian Company ${ }^{171}$, el poco epistolario conservado entre ambos hace pensar que no llegaron a forjar una relación continuada. En cualquier caso, el hecho de expresar públicamente la voluntad del primero de incorporar estos instrumentos ante críticos, músicos e incluso representantes del gobierno durante la conferencia en el Ateneo de Madrid ${ }^{172}$, indica que el musicólogo confiaba en la certeza de lo que decía.Y es que algunos diarios madrileños, como El Sol, recogieron la voluntad de Falla: "Subirá examinó la historia del instrumental que compone la 'cobla', con sus típicos instrumentos catalanes

\footnotetext{
${ }^{164}$ Granada, Archivo Manuel de Falla, "Festival de música catalana en honor de Manuel de Falla", top. 1927_0017.

165 "La filadora de Joan Lamote de Grignon y Triana de Isaac Albéniz,partituras para banda", Barcelona, L'Auditori, Arxiu de la Banda Municipal de Barcelona.

166 "Espectáculos", La Vanguardia, Barcelona, 10-1-1931, p. 20.

167 "Mirador teatral", Mirador, n. ${ }^{\circ}$ 130, Barcelona, 22-1-1931, p. 5.

168 "Conmemoración del primer aniversario de la República Española", La Libertad, Madrid, 15-41932, p. 3; "Magnífico concierto por la Cobla de Barcelona", El Heraldo de Madrid, 15-4-1932, p. 1.

${ }^{169}$ Centre de Documentació de l'Orfeó Català, Fondo Francesc Pujol, Programa "Concierto de música catalana a cargo de la Cobla Barcelona para el jueves 13 de abril de 1932, Ateneo de Madrid", top. R432

${ }^{170}$ José Subirá: "Las coblas ampurdanesas", La Sardana, Barcelona, 4-1932, pp. 146-149.

${ }_{171}$ Granada, Archivo Manuel de Falla, Epistolario José Subirá a Manuel de Falla, 18-2-1927, top.7659-001.

172 "Conmemoración del primer aniversario de la República Española", La Libertad, Madrid, 15-41932, p. 3; "Magnífico concierto por la Cobla de Barcelona", El Heraldo de Madrid, 15-4-1932, p. 1.
} 
(flaviol, tiple y tenora) [...] y señaló el hecho de que Falla incluya esos instrumentos en la vasta composición que actualmente escribe sobre el poema La Atlántida de Verdaguer" ${ }^{173}$.

El tercer indicio es un escrito del guitarrista Regino Sainz de la Maza, publicado en la revista Vértice en octubre de 1939, pocos días después de que Manuel de Falla cogiera el barco con destino a Argentina. Sainz de la Maza y Falla se habían conocido a través de la Sociedad Nacional de Música, concretamente en un concierto que había hecho el guitarrista el 24 de abril de 1920 en Madrid ${ }^{174}$. El artículo expone nuevamente la voluntad de Falla de incorporar los instrumentos de la cobla en Atlántida:"Pedrell, Morera, Pahissa, Millet y sobre todo Garreta, han conseguido verdaderas obras maestras con esta danza, enriqueciéndola con todos los recursos de la armonía moderna. Falla, en su magno poema sinfónico La Atlántida ha entronizado los instrumentos de la cobla en algunos pasajes" ${ }^{175}$. El contenido del artículo evidencia que Sainz de la Maza conocía la cobla. Por un lado, el músico vivió en Barcelona durante trece años, aproximadamente de 1916 a 1929; "Fueron años decisivos para mi formación artística y humana"176. Por otro lado, su hermano Eduardo compuso sardanas, unas obras que la Cobla Barcelona incluyó en su repertorio ${ }^{177}$.

Los tres indicios, junto con la certeza de que Falla había conocido la peculiaridad tímbrica de la cobla en instituciones que él mismo había legitimado públicamente, permiten sustentar la hipótesis de que el músico tenía la voluntad de incluir estos instrumentos en Atlántida, o por lo menos, la había tenido antes de partir a Argentina.

\section{Los manuscritos de Atlántida}

Los manuscritos conservados en el Archivo Manuel de Falla, unas doscientas páginas, incluyen borradores, bocetos, material para la composición, secciones completas e incluso fragmentos instrumentados. "Los manuscritos dicen más de lo que conocemos hoy a través de partituras editadas" relata Vallejo ${ }^{178}$, una idea que de Persia ha seguido desarrollando: "A pesar del desorden, los manuscritos son muy ricos y dicen mucho más de lo que conocemos hoy ante la carencia de nuevos estudios" ${ }^{\prime 179}$.

\footnotetext{
173 "Concierto de Música Catalana en el Ateneo", El Sol, Madrid, 16-4-1932, p. 2.

${ }^{174}$ José Leopoldo Neri de Caso: Regino Sainz de la Maza (1896-1981) y el renacimiento español de la guitarra en el siglo XX, tesis doctoral, Valladolid, Universidad de Valladolid, 2014, p. 39

175 Regino Sainz de la Maza: "Sardana”, Vértice, 26, San Sebastián, 10-1939, p. 34.

${ }^{176}$ Paloma Sainz de la Maza: Regino Sainz de la Maza, semblanza de mi padre, Burgos, Artes Gráficas Santiago Rodríguez, 1982, p. 33.

177 Sabadell, Músics per la Cobla, Arxiu Cobla Barcelona.

178 José Vallejo: Atlántida, sonido y materia, Granada, Archivo Manuel de Falla, 2008, p. 14.

${ }^{179}$ J. de Persia: "Atlántida, a on ets...?”, pp. 103-119.
} 
En los manuscritos constan varias melodías provenientes de libros de temática diversa que el compositor consultaba mientras componía. En cuanto a la cultura catalana, en el manuscrito C42 aparecen melodías extraídas de la Obra del Cançoner Popular de Catalunya: El pastoret, El comte Arnau, Muntanyes regalades, El testament de n'Amèlia, La pastoreta, L'hereu Riera o El rossinyol ${ }^{180}$. Cabe destacar que ya había escuchado algunas de ellas, como L'hereu Riera, El comte Arnau y Muntanyes regalades, en la versión coral de Josep Comellas Ribó, Josep Sancho Marraco y Lluís Millet durante el concierto celebrado en el Teatro Olympia en $1927^{181}$.

En determinadas ocasiones, Falla relató que la sustancia o esencia de la música se encontraba en los diferentes modos, cadencias, enlaces de acuerdos, ritmos y giros melódicos de las melodías populares de cada región ${ }^{182}$ : "Mi intento no es otro, el de extraer (¡y cuán laboriosamente!) la sustancia escondida en la música natural para procurar convertirla en música de arte" 183 . Aunque el compositor utilizó en contadas ocasiones la cita textual del documento popular, sorprende el uso que hizo de algunas melodías catalanas en El somni d'Isabel. En el manuscrito A58, después de la frase "terra en fora, terra en fora, l'he seguit fins a la mar" ${ }^{184}$, hay un giro melódico y rítmico que evoca El mariner (ejemplos 1 y 2). En el manuscrito A90, que contiene de nuevo un borrador de El somni d'Isabel, aparece un giro melódico y rítmico que evoca la melodía El bon caçador (ejemplos 3 y 4). Ambas melodías aparecen en el Cançoner popular editado en marzo de 1903 por Aureli Capmany, una edición que Pelai Mas -hijo del fotógrafo Adolf Mas- regaló a Falla en $1924^{185}$, y que según Nommick fue consultada para componer Atlántida ${ }^{186}$.

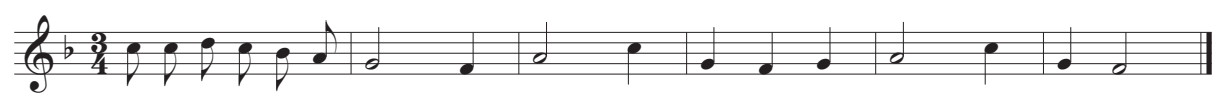

Ejemplo 1. Fragmento de la melodía de Lo mariner. Aureli Campmany: Cançoner Popular, $n .^{\circ} 34$

\footnotetext{
${ }^{180}$ Granada, Archivo Manuel de Falla, Manuscritos de Atlántida, top. C42.

${ }^{181}$ Ibid., "Festival de música catalana en honor de Manuel de Falla", top. 1927_0017.

182 Manuel de Falla: Escritos sobre música y músicos, introducción y notas de Federico Sopeña, 4. a edición, Madrid, Espasa-Calpe, 1988, pp. 56-176.

183 Granada, Archivo Manuel de Falla, Correspondencia, Falla a Joan Llongueras, 21-1-1927, top. 7224-012.

${ }^{184}$ Ibid., Manuscritos de Atlántida, top. A58.

${ }^{185}$ Aureli Capmany: Cançoner popular. Vol. 1, Barcelona, Tip. L’Avenç, 1903. La edición conservada en el Archivo Manuel de Falla (top. R1478) incluye una dedicatoria de Pelai Mas: "Al mestre Falla, penyora d'estima. Arxiu Mas, Barcelona, diada de Tots Sants de 1924".

${ }^{186}$ Y. Nommick: "LAtlantide...", 2006, p. 190.
} 


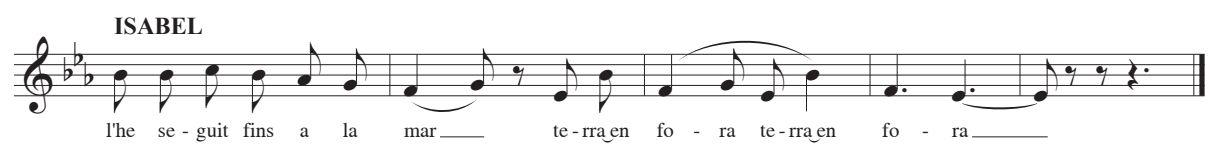

Ejemplo 2. Manuscrito de Atlántida, borrador de El somni d'Isabel, top. A58 (Archivo Manuel de Falla. Transcripción del autor)

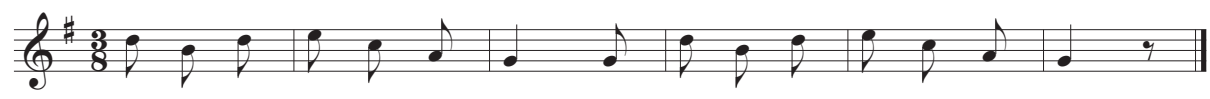

Ejemplo 3. Fragmento de la melodía de El bon caçador. Aureli Campmany:

Cançoner Popular, $n .^{\circ} 31$

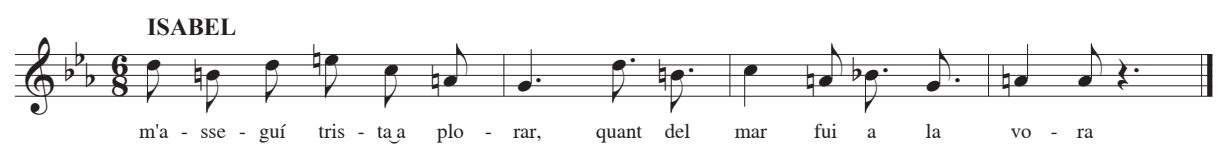

Ejemplo 4. Manuscrito de Atlántida, borrador de El somni d'Isabel, top. A90 (Archivo Manuel de Falla. Transcripción del autor)

La melodía que abre el manuscrito A101, titulado Cataluña, lleva por denominación "sardana-tarantela (vivo)" y un apunte, "Materiales, 269"187. Falla incorporó varios números y códigos de referencia en los manuscritos para recordar la procedencia del material musical. En ese caso, la melodía proviene de la página 269 de los volúmenes de la Obra del Cançoner Popular de Catalunya, editado en Barcelona en 1928 por la Fundación Concepció Rabell i Cibils, concretamente el fascículo 2, titulado "Materials. Memòries de Missions de recerca, estudis monogràfics i cròniques" $" 188$. De este libro, Falla copió una sardana ${ }^{189}$, una tonada proveniente de La Cellera de $\operatorname{Ter}^{190}$ - A la plaça n'hi ha balles- y dos melodías del trovador Raimbaut de Vaqueiras ${ }^{191}$. La tonada de La Cellera y las dos melodías de Raimbaut fueron copiadas textualmente, mientras que la sardana, que llevaba por nombre Els Aranyons y provenía de Sant Joan de les Abadesses ${ }^{192}$ fue modificada por el compositor, lo que confirma el procedimiento expuesto por Nommick: Falla adaptaba y modificaba

${ }^{187}$ Granada, Archivo Manuel de Falla, Manuscritos de Atlántida, top. A101.

${ }^{188}$ Joan Llongueras, Higini Anglès, Pere Bohigas, Jaume Massó, Lluís Romeu, Francesc Pujol, y Joan Puntí: Materials. Memòries de missions de recerca, estudis monogràfics, cròniques, vol. 1, fascicle II, Barcelona, Obra del Cançoner Popular de Catalunya, 1928.

${ }^{189}$ J. Llongueras et al., Materials..., p. 269.

190 Ibid., p. 75.

${ }^{191}$ Ibid., pp. 388-389.

192 Ibid., p. 365. 
el material intertextual para un posible uso ${ }^{193}$. Para indicar el tempo vivo de la danza, Falla añadió: "tarantella (vivo)". Además, transportó la canción de La menor a Fa menor y confeccionó una coda a partir del material de la misma melodía. Al mismo fragmento añadió un regulador de dinámica, así como también diversos acentos. De las tres tonadas copiadas, Falla sólo destacó con una cruz la sardana, lo que parece indicar nuevamente que la encontró interesante ${ }^{194}$.

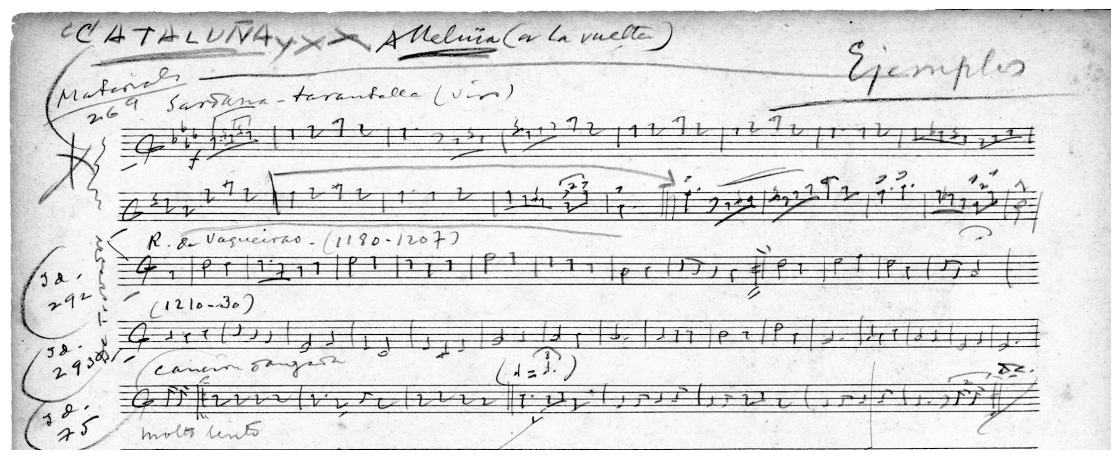

Ilustración 8. Manuscrito de Atlántida (Archivo Manuel de Falla)

Juan Viniegra relató que durante la década de 1930 se había dibujado un plano del claustro del monasterio de Poblet en el que, además de incluir la ubicación de la orquesta y de otros elementos, se había proyectado una plataforma donde, al parecer, se efectuarían algunas danzas ${ }^{195}$. Este hecho indica que es probable que Falla tuviera la intención, al menos durante la década de 1930, de incluir algunos números de danza en Atlántida. Así pues, no es extraño que anotara la tonada de una sardana en los manuscritos para tener material a partir del cual componer.

En el manuscrito A105, titulado Hespérides, encontramos el borrador de Els jocs de les Plèiades. Este fragmento, que fue revisado expresamente por el poeta catalán Josep Maria de Sagarra ${ }^{196}$, corresponde al segundo canto de Atlántida, dondeVerdaguer narra el momento en que Hércules visita el Jardín de las Hespérides $^{197}$ para robar las naranjas de oro custodiadas por las ninfas ${ }^{198}$.

${ }^{193}$ Y. Nommick: "L'Atlantide...", p. 174. "Il s’agit en général d'adaptations de matériaux intertextuels en vue d'une éventuelle utilisation".

${ }^{194}$ A. Budwig: "Una metodología...", p. 3. Según Budwig, Falla señalaba todo aquello que le interesaba con un corchete hecho al margen o una cruz.

195 J. Viniegra: Vida intima..., p. 253.

${ }^{196}$ L. Busquets: "El mito"..., p. 171; A. Budwig: Manuel de Falla's..., p. 301.

${ }^{197}$ E. Weber: “Colón...", pp. 135-136; L. Busquets: "El mito"..., p. 171.

${ }^{198}$ Durante el primer tercio del siglo XX, algunos artistas plasmaron este momento mitológico en obra plástica. Uno de ellos fue Antoni Gaudí, que a inicios del siglo X, diseñó un jardín para Eusebi Güell a las afueras de Barcelona, que fue conocido con el nombre de Jardín de las Hespérides; El País, Barcelona, 10-6-2015. 
Verdaguer situó el inicio de este canto en Tarragona -“"s'embarca, y prompte, al vèurel passar Tarraco antiga" 199 -, una ciudad que Manuel de Falla había visitado con Rafael Moragas en $1925^{200}$.Y es que, durante la década de 1930, Falla y Sert se habían llegado a plantear representaciones parciales al aire libre, concretamente en Tarragona, en Barcelona y en el monasterio de Poblet:

El Liceo, a pesar de todo, reúne condiciones hasta ahora inmejorables. Luego, después del estreno, sí podríamos hacer representaciones totales o parciales en la Plaza del Rey y hasta en Poblet y en la Pedrera de Tarragona. ¿Recuerda usted aquel proyecto de representar (después del estreno) cada una de las tres partes en un distinto sitio adecuado a ellas? El Prólogo y la primera parte podrían hacerse en la Pedrera y ante el mar. ¡Sería espléndido! ${ }^{201}$.

La parte inicial del fragmento musical conservado en el manuscrito A105, Hespérides, contiene varias características estilísticas que recuerdan a la escritura musical concebida como catalana. Para componer este movimiento, Falla se inspiró en un juego. Así lo anotó en el manuscrito “juli!'”. Falla, que había leído el fragmento "Balla y presum d'Hespèrides lo tendre poncellam, / joguineja ab cireres y pomes per la molsa, / y, juli! a salts abasta taronges del brancam" ${ }^{202}$, no comprendió el significado de la palabra juli y pidió ayuda a Francesc Blanch ${ }^{203}$. En diciembre de 1928, Blanch le respondió: "Respecto a la pregunta que me hace referente al juego de la comba, que en catalán se denomina 'Saltar la corda', la voz 'juli' es una exclamación que se emplea para acelerar el movimiento o el salto" 204.

Uno de los aspectos más cuestionados de Atlántida es la orquestación.Y es que Falla tan solo dejó instrumentado el Prólogo y algunos compases de Hymnus hispanicus ${ }^{205}$. En los manuscritos aparecen algunos fragmentos instrumentados, así como también varias indicaciones de instrumentación. Ernesto Halffter, además de incluir varios números de creación personal, llevó a cabo la totalidad de la orquestación de Atlántida.Vallejo expone que Falla comenzó a

El arquitecto también lo plasmó en la puerta de la Finca Güell; Jeremy Roe: Antoni Gaudí - El máximo exponente de la arquitectura modernista catalana, Barcelona, Parkstone International, 2019.

${ }^{199}$ J. Verdaguer: L'Atlàntida..., p. 53. "Embárcase, y, no bien le divisa pasar la antigua Tarraco" (traducción castellana de Melchor de Palau incluida en la misma edición).

${ }^{200}$ Granada, Archivo Manuel de Falla, Correspondencia Manuel de Falla a Rafael Moragas, top. 7303060(1).

${ }^{201}$ Granada, Archivo Manuel de Falla, Correspondencia, Falla a Sert, 2-8-1935, top. 7619-2-039(1).

202 J. Verdaguer: L'Atlàntida..., p. 64. "Danza y retoza el juvenil corro de Hespérides; con pomas y cerezas juega en el musgo, y, saltando, desprende naranjas del ramaje" (traducción castellana de Melchor de Palau incluida en la misma edición).

${ }^{203}$ Granada, Archivo Manuel de Falla, Correspondencia, Falla a Francesc Blanch, 20-12-1928, top. 6771-004.

${ }^{204}$ Ibid., 23-12-1928, top. 6771-003.

${ }^{205}$ Granada, Archivo Manuel de Falla, Manuscritos de Atlántida, CII A1, CII A2, CII C1, CII C2, CII A3 i CII C4. 
instrumentar la obra meses antes de morir, es decir, en $1946^{206}$. El mismo autor relata que algunos números de creación propia de Halffter incrementaron en exceso el volumen de la obra y evidenciaron cierta heterogeneidad sonora. Edmon Colomer, que consideró afortunada la instrumentación de Halffter, también cuestionó algunos aspectos musicales de la obra:

La segunda parte es la que ha sido más elaborada por Halffter, es la que plantea los problemas más importantes de equilibrio formal y pone en evidencia las diferencias conceptuales con Falla [...]. El problema estructural de la obra no tiene sus raíces solo en la forma, sino también en el uso de fórmulas rítmicas, armónicas, melódicas y tímbricas, que no siempre tenían en cuenta el universo sonoro que Falla había concebido para las partes terminadas ${ }^{207}$.

Budwig se mostró muy crítico con la orquestación que había realizado Halffter. Según el autor, el manuscrito de El somni d'Isabel incluía pistas de instrumentación que designaban una plantilla formada por un conjunto de cámara que compartía múltiples semejanzas con las que había utilizado durante el período neoclásico ${ }^{208}$. Según Budwig, Halffter, bajo la idea personal de volver a componer en lugar de conservar y editar, amplió la orquestación de este número sin tener en cuenta las anotaciones del compositor. Nommick manifestó que Parsifal de Wagner fue uno de los modelos durante la composición de Atlántida $a^{209}$. La instrumentación del Prólogo abraza la plantilla instrumental más amplia de toda su producción, así lo destaca Nommick: "Su nomenclatura instrumental es considerable y permite una sonoridad llena, honda y sólida [...]. La ausencia total de lo pintoresco se suma a la expresión de profundidad y gravedad"210. La plantilla del Prólogo ideada por Falla -que no incluye ni tenora ni tiple ${ }^{211}$ - fue modificada nuevamente por Halffter, quien añadió varios instrumentos de percusión y modificó la instrumentación de algunos pasajes ${ }^{212}$. Aunque en algunos manuscritos aparecen algunas indicaciones de instrumentación, así como también tesituras de algunos instrumentos en concreto, como la viola de gamba o la viola d'amore ${ }^{213}$, en ninguno de los doscientos aparece la palabra tenora o tiple.

\footnotetext{
${ }^{206}$ J. Vallejo: Atlántida, sonido..., p. 32.

${ }^{207}$ E. Colomer: notas al disco Manuel de Falla: Atlàntida..., pp. 15-17.

208 A. Budwig: Manuel de Falla's..., p. 39.

${ }^{209}$ Y. Nommick: "L'évolution des effectifs...", pp. 333.

${ }^{210} \mathrm{Ibid}$ : "Sa nomenclature instrumentale est considérable et permet une sonorité pleine, fondue, solide [...]. Par ailleurs, l'absence totale de pittoresque ajoute à l'expression de la profondeur et de la gravité".

${ }^{211}$ Granada, Archivo Manuel de Falla, Manuscritos de Atlántida, CII A1, CII A2, CII C1, CII C2, CII

212 Y. Nommick: "Lévolution des effectifs...", pp. 326.

${ }^{213}$ Granada, Archivo Manuel de Falla, Manuscritos de Atlántida, top. C15v.
} A3 i CII C4. 


\section{Conclusiones}

Manuel de Falla mostró interés en todo lo que rodeaba la cobla y la sardana. Por un lado, conoció la peculiaridad tímbrica de la cobla en los diferentes conciertos y ensayos a los que asistió. Por otro lado, guardó documentación referente a esa temática: las instrucciones y las tesituras redactadas por Lambert, las dos sardanas del mismo músico o la Sonata en do menor de Garreta, que incluye una sardana en el tercer tiempo. También nos lo confirman las gestiones que hizo el compositor para que Mary Wiborg consiguiera las sardanas para piano, así como también la proposición que hizo durante la década de 1940 a Jaume Pahissa para que escribiera una. Algunas instituciones, como la Banda Municipal de Barcelona y la Cobla Barcelona, intentaron seducir a Falla para que escribiera alguna sardana, unas propuestas que, desgraciadamente, no llegó a realizar.

Aunque los testimonios de sus contemporáneos permiten plantear la hipótesis de que Falla tenía la voluntad de incorporar la sonoridad tímbrica de los instrumentos catalanes en Atlántida, en los manuscritos conservados en el Archivo Manuel de Falla no aparece ninguna indicación que lo constate. Todo hace pensar que la voluntad de incluir estos instrumentos pudo haber existido durante la década de 1930 y que se podía haber diluido durante su posterior estancia en Argentina.Y es que Falla comenzó a instrumentar el Prólogo en $1946^{214}$, quince años después del concierto en el Palau de Belles Arts. Sin embargo, durante la década de 1930, mostró mucho interés en que la obra fuera estrenada en Cataluña y que, tras el estreno, fuera representada en diferentes espacios del territorio catalán, donde habría sido fácil encontrar intérpretes para una posible ejecución.

El carácter reservado del músico dificulta la obtención de más pruebas que ayuden a verificar los indicios expuestos. Incluso Pahissa, que había tratado con Falla durante la última etapa de su vida, no relató nada referente a la inclusión de los instrumentos catalanes en la obra. Más bien afirmó que nadie sabía nada de la música de Atlántida: "Nadie conoce nada. Falla es demasiado meticuloso y pulcro en su trabajo para mostrar una obra que él no cree terminada" ${ }^{215}$. Sin embargo, Subirá y Sainz de la Maza mencionaron públicamente que Falla tenía el propósito de incorporar esos instrumentos a la obra, algo que el compositor no llegó a desmentir.

Sea como sea, el aspecto masivo de gran orquesta que proyectó Falla en la instrumentación del Prólogo hace pensar que la obra podría haber tenido momentos orquestales importantes y haber incluido otros tipos de instrumentos, como la tenora o el tiple. Sin conocer si Halffter sabía algo sobre la voluntad de Falla, podemos afirmar que aquel también mostró interés en la sonoridad de la cobla. Pocos años después de estrenar Atlántida Halffter instrumentó para

\footnotetext{
${ }^{214}$ J. Vallejo: Atlántida, sonido..., p. 32.

215 Jaume Pahissa: Vida y obra de Manuel de Falla, Buenos Aires, Ricordi Americana, 1956, p. 163.
} 
orquesta sinfónica Danzas españolas de Enric Granados y en la número 4, titulada Villanesca, incorporó los instrumentos de la cobla ${ }^{216}$, versión que fue grabada en 1966 por la Orquesta Sinfónica de Radio Televisión Española y la Cobla Barcelona, bajo la batuta de Igor Markevitch ${ }^{217}$.

\section{Bibliografía}

Almacellas, Josep Maria: Banda Municipal de Barcelona: 1886-1944: del carrer a la sala de concerts, Barcelona, Arxiu Municipal de Barcelona, 2006.

ArCAs, Ana María: Escenografia en la música de Manuel de Falla: del Amor brujo al Retablo de maese Pedro, tesis doctoral, Sevilla, Universidad de Sevilla, 2017.

AviñoA, Xosé: Jaume Pahissa, un estudi biogràfic i crític, Barcelona, Biblioteca de Catalunya, 1996.

Budwig, Andrew: "Una metodología para el estudio de la Atlántida de Manuel de Falla", Revista de Musicología, 1, 1982, pp. 155-162.

-: Manuel de Falla's Atlántida: an historical and analytical study, tesis doctoral, Chicago, University of Chicago, 1984.

BusqueTs, Loreto: “El mito de Atlántida: de Verdaguer a Falla y Halffter”, Studi Ispanici, 2006, pp. 157-194.

CAPMAnY, Aureli: Cançoner popular. Volum 1, Barcelona, Tip. L'Avenç, 1903.

Carredano, Consuelo: "Devociones ejemplares: algunas pautas en la relación de Manuel de Falla y Ernesto Halffter”, Cuadernos de Música Iberoamericana, 11, 2006, pp. 17-50.

Colomer, Edmon: notas al disco Manuel de Falla:Atlàntida [CD], Joven Orquesta Nacional de España, Edmon Colomer (dir.), Auvidis Valois, 1993.V4685.

Christoforidis, Michael: Manuel de Falla, Madrid, Fundación Autor, 1998.

Demarquez, Suzanne: Manuel de Falla, París, Flammarion, 1963.

Etcharry, Stéphan: “Atlántida ou le testament inachevé de Manuel de Falla”, comunicación presentada en el coloquio internacional "La musique et l'ultime: esthétique des dernières œuvres”,Évry, Université d'Évry-Val-d'Essonne, 8-9 diciembre 2015, editado y publicado en línea en 2018, pp. 1-16, https://univ-reims.academia.edu/ETCHARRYStéphan.

Falla, Manuel de: Escritos sobre música y músicos, introducción y notas de Federico Sopeña, $4^{a}$ edición, Madrid, Espasa-Calpe, 1988.

Fontelles-Ramonet, Albert: "La sardana segons Joaquín Turina”, Revista Catalana de Musicologia, 13, 2020,pp. 257-287.

—: La Cobla Barcelona (1922-1938). Un projecte noucentista, tesis doctoral, Universitat Autònoma de Barcelona, 2020.

216 "Danza número 4: Villanesca, partitura para orquesta sinfónica y cobla catalana", Madrid, Biblioteca de la Fundación Juan March, Legado de Ernesto Halffter. Según la documentación conservada en su legado, para la instrumentación, Halffter pidió asesoramiento al compositor catalán Tomàs Gil i Membrado, interprete de la Cobla Barcelona.

${ }^{217}$ Madrid, Biblioteca Nacional de España, Fonogramas, top. M 15543-1969. 
Franco, Enrique: Amadeo Vives (1871-1971), Madrid, Sociedad General de Autores de España, 1972.

Galiano, Juan Carlos: “El amor brujo en el repertorio actual de banda (2006-2015): hacia un estado de la cuestión”, El amor brujo, metáfora de la modernidad: estudios en torno a Manuel de Falla y la música española del siglo XX, Madrid, Centro de Documentación de Música y Danza, INAEM / Granada, Archivo Manuel de Falla, 2017, pp. 499-518.

Galdego, Antonio: Catálogo de obras de Manuel de Falla, Madrid, Dirección de Bellas Artes y Archivos, Ministerio de Cultura, 1987.

GARCía de PAREDES, Ángela: “Atlántida sumergida”, Revista Europea de Investigación en Arquitectura, 6, 2016, pp. 58-71.

García López, Olimpia: "Los conciertos en la Exposición Iberoamericana de Sevilla (19291930): un acercamiento a través de la prensa”, Imagen, escenografía y espectáculo en la Exposición Iberoamericana: testimonios, artistas y manifestaciones, Sevilla, Editorial Universidad de Sevilla, 2018, pp. 155-182.

García Matos, Manuel:“El folklore en 'La vida breve' de Manuel de Falla”, Anuario Musical, 26, 1971,pp. 173-197.

—: "Folklore en Falla", Revista trimestral de los conservatorios españoles, 3, 4, 1953, pp. 41-68.

Hoffelé, Jean-Charles: Manuel de Falla, París, Fayard, 1992.

Jамвоu, Louis: “Arquetipos hispanos en la obra de Manuel de Falla”, Manuel de Falla: latinité et universalité. Actes du Colloque International tenu en Sorbonne, 18-21 novembre 1996, Louis Jambou (dir.), París, Université Paris X, 1999, pp. 389-404.

JimÉnEz, Lourdes: El reflejo de Wagner en las artes plásticas españolas. De la Restauración a la Primera Guerra Mundial, tesis doctoral, Universitat de Barcelona, 2013.

Llongueras, Joan; Anglès, Higini; Bohigas, Pere; Massó, Jaume; Romeu, Lluís; Pujol, Francesc; PunTí,Joan: Materials. Memòries de missions de recerca, estudis monogràfics, cròniques, vol. 1, Fascicle II, Barcelona, Obra del Cançoner Popular de Catalunya, 1928.

Llort Llopart,Victòria:"La emoción estética en Atlántida de Manuel de Falla: horror, exaltación y religiosidad”,Iberic@l. Revue d’Études Ibériques et Ibéro-Américaines, 2014,pp. 77-88.

Manzano, Miguel:"Fuentes populares en la música de 'El sombrero de tres picos', de Manuel de Falla", Nassarre, 9, 1, 1994, pp. 119-144.

—: La jota como género musical, Madrid, Alpuerto, 1995.

MARCO, Tomás: "Falla y la utilización del material tradicional en la composición actual”, Manuel de Falla: latinité et universalité. Actes du Colloque International tenu en Sorbonne, 18-21 novembre 1996, Louis Jambou (dir.), París, Université Paris X, 1999, pp. 563-575.

Mejías, Enrique: "Manuel de Falla en el contexto del género chico madrileño: nuevas respuestas a un viejo problema”, Quodlibet, 55, 2014,pp. 7-39.

Montiel, Teresa: "Sergei Diághilev, la renovación del Ballet”, ArtyHum. Revista de Artes y Humanidades, 24, 2016, pp. 93-104.

MuntadA, Marta: L'Associació Música “Da Camera” (1913-1936), tesis de licenciatura, Universitat de Barcelona, 1984.

Neri de CASo, José Leopoldo: Regino Sainz de la Maza (1896-1981) y el renacimiento español de la guitarra en el siglo XX, tesis doctoral, Universidad de Valladolid, 2014. 
Nomмicк,Yvan:"El influjo de Felip Pedrell en la obra y en el pensamiento de Manuel de Falla", Recerca Musicologica, 14-15, 2004, pp. 289-300.

-: "L'Atlantide de Manuel de Falla: du mythe platonicien à la bibliothèque mythique", Pensée mythique et création musicale, Marie-Pierre Lassus (ed.), Lille, Université Charles de Gaulle, 2006, pp. 179-191.

-: "L'évolution des effectifs instrumentaux dans l'œuvre de Manuel de Falla: continuité ou discontinuité", Manuel de Falla: latinité et universalité. Actes du Colloque International tenu en Sorbonne, 18-21 novembre 1996, Louis Jambou (dir.), París, Université Paris X, 1999, pp. 323-338.

-: "La herencia de la música y el pensamiento de Manuel de Falla en la posguerra (19401960)", Actas del congreso "Dos décadas de cultura artística en el Franquismo (1936-1956)", Ignacio de Henares Cuéllar, María Isabel Cabrera García, Gemma Pérez Zalduondo, José Castillo Ruiz (dirs.), Granada, Universidad de Granada, 2001, pp. 9-30.

Pahissa, Jaume: Vida y obra de Manuel de Falla, Buenos Aires, Ricordi Americana, 1956.

Persia, Jorge de:“Atlántida, a on ets...?”, Quodlibet, 55, 2014, pp. 101-131.

Rabaseda, Joaquim; Fontelles-Ramonet, Albert: "El ball de gegants de Solsona i la invenció d'un gènere musical”, Oppidum: Revista Cultural del Solsonès, 16, 2018, pp. 86-101.

Rodríguez, Rosa Maria: Més enllà de la cobla: el repertori per a tenora en formacions simfoniques, trabajo final de grado, Barcelona, Escola Superior de Música de Catalunya, 2019.

Roe, Jeremy: Antoni Gaudí - El máximo exponente de la arquitectura modernista catalana, Barcelona, Parkstone International, 2019.

Sainz de la Maza, Paloma: Regino Sainz de la Maza, semblanza de mi padre, Burgos, Artes Gráficas Santiago Rodríguez, 1982.

SAPERAS, Miquel: El mestre Enric Morera, Barcelona, Socitra, 1969.

SAumell, Mercè: El Teatre Contemporani, Barcelona, Editorial UOC, 2006.

SCHEFER, Olivier: Variations on Totality: Romanticism and the Total Work of Art, Baltimore, Johns Hopkins University Press, 2011.

Torres, Elena: "Manuel de Falla en la creación musical catalana: asimilación y superación de un modelo", Música española entre dos guerras, 1914-1945, Emilio Casares Rodicio, Javier Suárez-Pajares (coords.), Granada,Archivo Manuel de Falla, 2002, pp. 79-96.

Vallejo, José:Atlántida, sonido y materia, Granada,Archivo Manuel de Falla, 2008.

Verdaguer, Jacint: L'Atlàntida, Barcelona, Estampa de la Casa Miquel-Rius, 1929.

Viniegra Juan: Vida íntima de Manuel de Falla, Cádiz, Diputación de Cádiz, 1966.

WeBER, Eckhard:“"Atlántida' de Manuel de Falla: nuevas soluciones para el teatro musical”, Anuari Verdaguer, 11, 2003, pp. 629-648.

- "Colón-El Cristoforus. Manuel de Falla, la Guerra civil y su cantanta escénica Atlántida", Quodlibet, 55, 2014,pp. 132-147.

Zimmermann, Marie-Claire: 'L'Atlàntida: poème en langue catalane revisité par Manuel de Falla”, Manuel de Falla: latinité et universalité. Actes du Colloque International tenu en Sorbonne, 18-21 novembre 1996, Louis Jambou (dir.), París, Université Paris X, 1999, pp. 111-121. 